\title{
Strength evaluation of prosthetic check sockets, copolymer sockets, and definitive laminated sockets
}

\author{
Maria J. Gerschutz, PhD; ${ }^{*}$ Michael L. Haynes, MS; Derek Nixon, BS; James M. Colvin, MS \\ The Ohio Willow Wood Company, Mt. Sterling, $\mathrm{OH}$
}

\begin{abstract}
A prosthesis encounters loading through forces and torques exerted by the person with amputation. International Organization for Standardization (ISO) standard 10328 was designed to test most lower-limb prosthetic components. However, this standard does not include prosthetic sockets. We measured static failure loads of prosthetic sockets using a modified ISO 10328 and then compared them with the criteria set by this standard for other components. Check socket (CS) strengths were influenced by thickness, material choice, and fabrication method. Copolymer socket (CP) strengths depended on thickness and fabrication methods. A majority of the CSs and all of the CPs failed to pass the ISO 10328 ductile loading criterion. In contrast, the strengths of definitive laminated sockets (DLs) were influenced more by construction material and technique. A majority of the DLs failed to pass the ISO 10328 brittle loading criterion. Analyzing prosthetic sockets from a variety of facilities demonstrated that socket performance varies considerably between and within facilities. The results from this article provide a foundation for understanding the quality of prosthetic sockets, some insight into possible routes for improving the current care delivered to patients, and a comparative basis for future technology.
\end{abstract}

Key words: amputation, carbon composite, central fabrication facility, copolymer socket, definitive laminated socket, diagnostic socket, International Organization for Standardization standard 10238, military facility, private practice facility, prosthetic materials, prosthetic socket, static failure force.

\section{INTRODUCTION}

Prosthetic sockets serve as the structural element connecting an individual's residual limb to his or her prosthesis. Even though a vast amount of research has been conducted on prosthetic socket interfaces [1-2], a limited amount of research evaluates the overall component strength of prosthetic sockets. Evaluating prosthetic socket material properties has been difficult because of the complex design and the application of irregular stress patterns [3]. While International Organization for Standardization (ISO) standards exist for most lower-limb prosthetic components, prosthetic sockets are not subject to any standard. Therefore, the socket strength is unknown and

Abbreviations: ANOVA $=$ analysis of variance, $\mathrm{CAD}=$ computer-aided design, CAM = computer-aided manufacturing, $\mathrm{CFAB}=$ central fabrication, $\mathrm{CP}=$ copolymer socket, $\mathrm{CS}=$ check socket, DL = definitive laminated socket, ISO = International Organization for Standardization, NHANES III = National Health and Nutrition Examination Survey release III, PETG = polyethylene terephthalate glycol, $\mathrm{PP}=$ private practice, $\mathrm{RSD}=$ relative standard deviation, $\mathrm{SD}=$ standard deviation, SMU = socket manufacturing unit.

*Address all correspondence to Maria J. Gerschutz, PhD; The Ohio Willow Wood Company, 15441 Scioto Darby Rd, PO Box 130, Mt. Sterling, OH 43143; 740-869-3377; fax: 740-869-4374. Email: mariag@owwco.com http://dx.doi.org/10.1682/JRRD.2011.05.0091 
could pose an unnecessary risk to the person with amputation.

While understanding the performance of prosthetic sockets is important to ensure production of quality prosthetic components, only a few studies have analyzed complete prostheses or prosthetic sockets. Current et al. tested laminate sockets with ISO 10328 loading conditions [4]. ISO 10328, which applies to a wide variety of prosthetic components, does not encompass prosthetic sockets [5]. However, ISO 10328 is generally considered the best reference available because it applies to the components that are attached to the socket. Current et al. performed static testing at A100 loads in condition II (brittle load criterion of 4,025 N), comparing five different reinforcement materials and two resins [4]. All 10 sockets tested in the study failed to pass the ISO 10328 static test [4]. The socket performance may have been influenced by the type of distal adapters $[4,6]$. The results from Current et al. indicate that the type of reinforcement material contributes to a socket's ultimate static strength performance, with carbon fiber producing higher strengths than fiberglass [4]. Coombes and MacCoughlan analyzed the complete prosthesis on thermoplastic sockets using the Philadelphia Static Load Test (2,500 N). This study concentrated on prosthetic shank designs rather than prosthetic sockets [7].

All of these studies took precautions to control fabrication variability. However, there is no standard regarding fabrication technique or material selection for prosthetic sockets. Facility and technique variability can drastically influence the quality and strength of the prosthetic sockets ultimately delivered to the patient.

Depending on the socket's purpose, there are a variety of socket types constructed from an array of materials. Diagnostic sockets (or check sockets [CSs]) are typically fabricated from thermoplastics, which include polyethylene terephthalate glycol (PETG, also known as Vivak [Bayer MaterialScience Gmbh; Darnstadt, Germany]), ThermoLyn rigid (Otto Bock HealthCare Gmbh; Duderstadt, Germany), and Orfitrans Stiff (Orfit Industries N.V.; Wijnegeno, Belgium). CSs are normally used for both static and dynamic socket fit evaluation. Polypropylene copolymer sockets (CPs, thermoplastic copolymer) are typically used as definitive sockets. This article uses the term "definitive" in relation to sockets to refer to a permanent socket delivered to the patient for long-term use. This definitive socket can be constructed from either thermoplastic or thermoset materials. Lami- nated socket materials are composites of reinforcement material (carbon fiber, nyglass, nylon, cotton stockinette, or fiberglass) and resin. These composite materials are generally only used to fabricate definitive sockets.

The purpose of this article is to analyze the current state-of-the-art of prosthetic socket performance by assessing static failure loads for CSs, CPs, and definitive laminated sockets (DLs). Past research has focused on DLs; however, CSs and CPs are used for dynamic testing and/or permanent usage. For this reason, we evaluated all three types of sockets. We made additional comparisons regarding individual facilities, type of facility, fabrication material and methods, and socket thickness.

\section{METHODS}

\section{Socket Design}

We used computer-aided design (CAD)/computeraided manufacturing (CAM) software to generate an electronic file for a residual limb that represented an anthropometric 98th percentile male as defined by data from the National Health and Nutrition Examination Survey release III (NHANES III). ${ }^{*}$ These values, determined from a sampling of the U.S. male population ( $\geq 20$ years old) from all ethnic groups, indicate the parameters that would include 98 percent of the male population. Recent updates to NHANES III made available since the start of this study indicate that the body mass for a 95th percentile male in the United States has increased by 11 percent in the 14 years between revisions. We extrapolated a generic transtibial residual limb template from OMEGA Tracer (The Ohio Willow Wood Company; Mt. Sterling, Ohio) to produce the anthropometric 98 percent male model. The extrapolation process resulted in a circumference at the patellar tendon bar and a length from the patellar tendon bar to the distal end of 52.4 and $19.2 \mathrm{~cm}$, respectively. The increased height and large dimensional socket provided a worst-case scenario for pulled sockets and also allowed for the incorporation of a flat popliteal

\footnotetext{
*National Health and Nutrition Examination Survey release III (NHANES III), 1988-1994 (updated 2008 May 5). Available from: http://www.docstoc.com/docs/547346/Table-Weight-in-pounds-formales-years-and-over-number-of-examined-persons-mean-standarderror-of-the-mean-and-selected-percentiles-by-race-ethnicity-andage-United-States-Anthropometric-Reference
} 
area, which was used in an additional material property study not presented in this article.

\section{Socket Providers}

We formulated study specifications using initial static testing results from a set of in-house fabricated sockets. We used initial analysis of the resulting in-house test data to estimate process variances. Using these variances and institutional experience with outside providers, we estimated the number of samples necessary to obtain statistical power between the three types of facilities of greater than 95 percent and power inside of each individual facility of approximately 70 percent. The in-house central fabrication (CFAB) facility did not serve as a participating facility, and data collected from the in-house sockets were strictly used for constructing the study specifications. Based on this analysis, we asked nine facilities (three CFAB, three private practice [PP], and three military/ Department of Veterans Affairs facilities) to participate in the study.

We requested that each facility supply four CSs, four CPs, and four DLs for testing. We sent the same CAD/ CAM file, previously described, to each facility along with a set of fabrication instructions. We did not provide the facilities with a description of the patient. Patient weight and height were available but never requested by any of the sites. The facilities used the CAD/CAM file to create positive foam models on which sockets were fabricated. We did not restrict material choice and fabrication methods for generating the positive foam model and sockets; this therefore represented the facility's standard process. We asked facilities to provide information about the method of fabrication, the materials used, and a sample of the raw materials used (for thermoplastic sockets).

For the thermoplastic sockets, the facilities used three different fabrication methods: blister forming, machine-pulled, and drape. The blister forming method consists of manually pulling an oven-heated thermoplastic sheet of material over a foam or plaster positive model oriented distal to proximal. Immediately after the material is pulled and while still pliable, it is vacuum-formed tightly over the model. The pulling process in the blister forming method results in an uneven material thickness distribution [8]. Machine-pulled methods perform this process in automated machines using preformed bellshaped thermoplastic materials. This preformed bell generally reduces the amount of stretching necessary, which leads to a more uniform socket thickness. The drape method manually drapes the oven-heated thermoplastic sheet of material over a foam or plaster positive model oriented anterior to posterior. The material is pinched together to form a seam on the posterior side and then vacuum formed to the model [8]. Depending on the individual facility, the thermoplastic sockets, for all three methods, may be quenched or allowed to room cool. For the DLs, all facilities laminated their sockets by saturating reinforcement materials (carbon fiber or fiberglass) with resin [9]. Vacuum is used to assist the saturation. The actual technique and lay-up was facility-dependent.

Both CFAB and PP facilities supplied all requested sockets. However, two military facilities only supplied three sockets of each type, and one of the military facilities did not supply CPs because CP use is not part of their standard practice. One DL was ruined during testing; thus, the total number used in the static testing analysis was 98 sockets.

\section{Socket Processing}

We labeled sockets upon receipt. The standard nomenclature for the study identifiers was the socket type's two-letter abbreviation followed by the facility number. For example, we identified CSs from the first facility as CS01. We recorded the material type and manufacturing method provided by each facility. A technician measured the raw socket (no trim lines) height. The same technician then hand drew trim lines on the sockets and removed excess material. We used the excess material in another study that analyzed material properties. We then remeasured the processed sockets' heights.

In order to conduct thickness correlation analyses, we measured thickness using a dial caliper gauge (range: 0-100 × $400 \mathrm{~mm}$, gradient: $0.10 \mathrm{~mm}$, model SG02, Tresna Instruments [Guilin Guanglu Measuring Instrument Co, Ltd; Guilin, China]). We took a total of 16 thickness measurements in the four predominant directions (anterior, posterior, medial, and lateral) and at four different height levels (flat distal plane, located at the four-hole distal attachment site; mid-distal cup region, approximately $1.5 \mathrm{~cm}$ above the distal plane; mid-socket wall, approximately $10.5 \mathrm{~cm}$ above the distal plane; and along the trim line, approximately $4 \mathrm{~cm}$ below in the anterior and posterior direction and $1.5 \mathrm{~cm}$ below in the medial and lateral direction). Figure 1(a) labels areas of interest, and Figure 1(b) illustrates, in the medial viewing plane, the location of thickness measurements. While Figure 1(b) was photographed after mechanical testing, we took all 

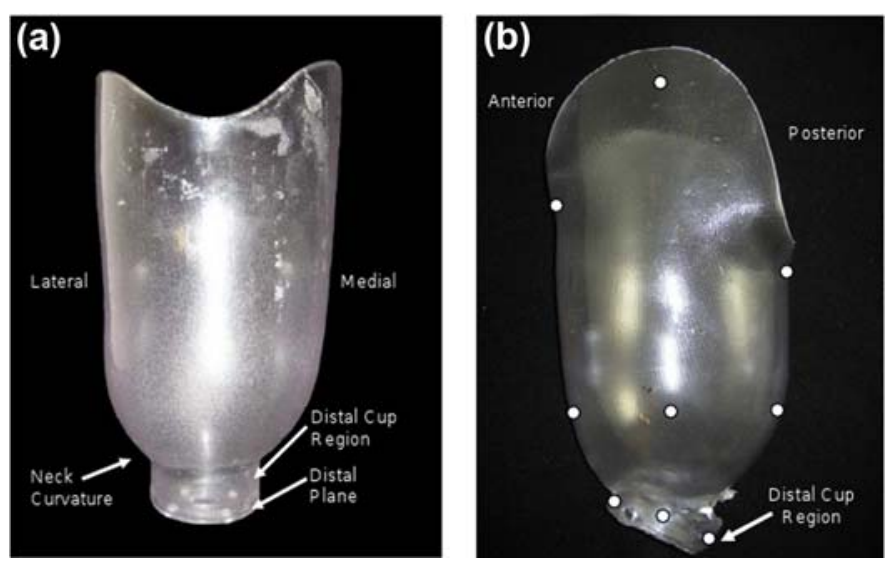

Figure 1.

(a) Sample check socket (CS) prior to static failure load testing with marked areas of interest. (b) Sample CS after static failure loading test. Socket thickness measurement sites indicated by dots. Only measurements sites visible in medial viewing plane are shown. Measurements taken prior to mechanical testing.

thickness measurements before mechanical testing. We conducted correlation analyses on thickness values measured along the middle of the distal cup region, which corresponded to the primary location of failure. Throughout the article, we refer to this measurement as the distal socket thickness.

\section{Socket Testing}

We measured static failure loads using an Interlaken 3300 series test frame with a series 3200 controller (Interlaken Technology Corporation; Chaska, Minnesota). We conducted tests in accordance with ISO 10328 condition II by applying a $4.5 \mathrm{~kg}(10 \mathrm{lb})$ preload, then ramped the load to failure at a rate of $250 \mathrm{~N} / \mathrm{s}$. Passing criteria were considered to be the values designated in ISO 10328 condition II A125 level (4,426 N for brittle failure and 3,421 $\mathrm{N}$ for ductile failure). We attached the socket to the pylon using a standard four-hole distal attachment plate; the loads were transferred by a simulated residual limb model. A cone-shaped aluminum mandrel with a $5^{\circ}$ tilt served as the core bone shape of the residual limb model. We casted the mandrel in a polyurethane (Repro One, Freeman Manufacturing \& Supply Co; Avon, Ohio), allowing us to position a $9 \mathrm{~mm}$ uniform silicone liner between the residual limb model and the prosthetic socket. Figure 2 presents a picture of the test setup. We noted any socket fit deviations in comparison with

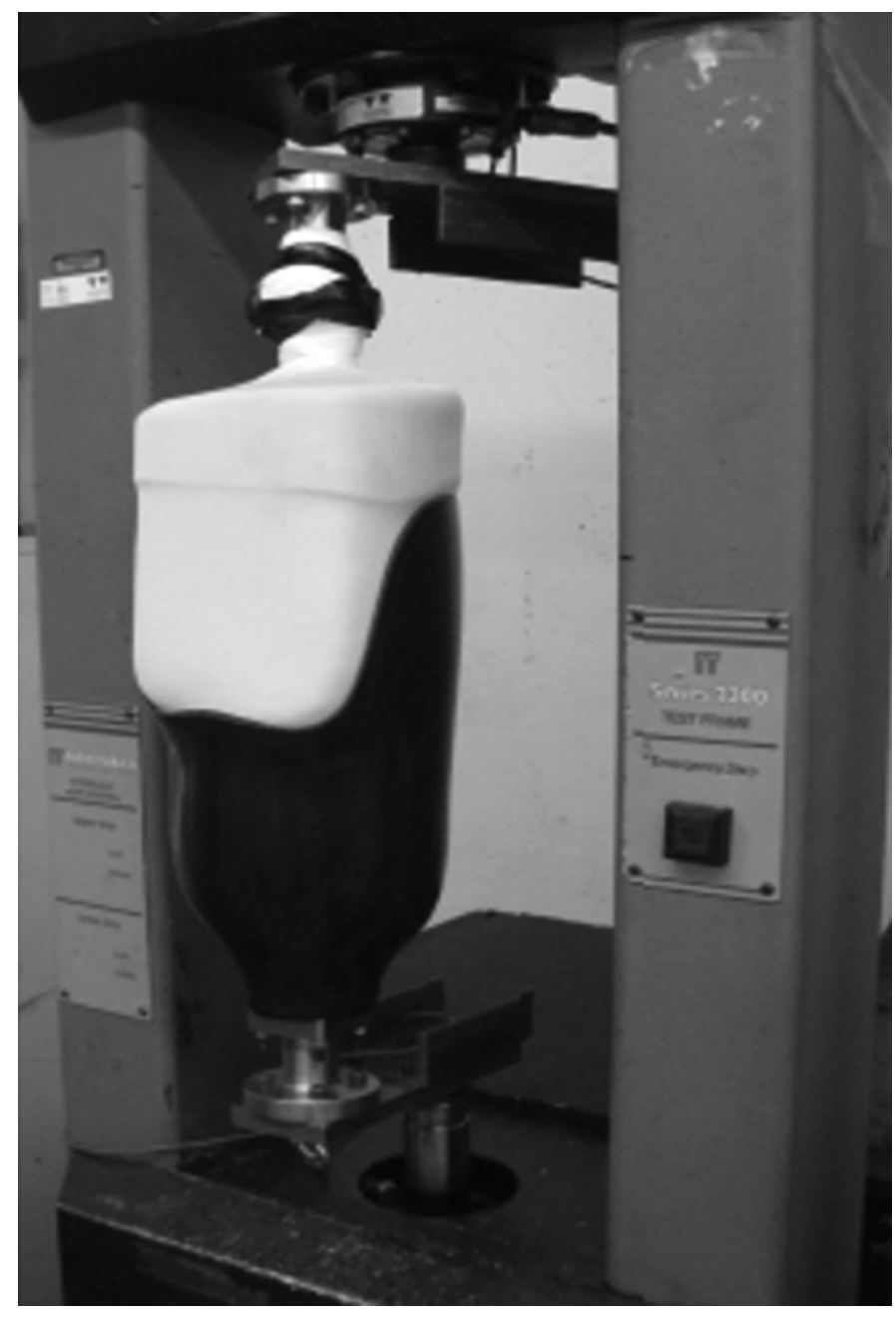

Figure 2.

Static socket testing configuration in accordance with International Organization for Standardization standard 10328.

the residual limb and liner condition before testing. The static failure test resulted in a force-deflection curve for each socket.

We analyzed the socket static testing by extracting the force inflection point on the force-deflection curve (Figure 3) that indicated yielding (the socket's yield strength). Using these force values, which represent the accumulation of permanent deformation that can lead to failure, we evaluated socket strength and analyzed the variance within a facility and the variance within the industry as a whole. We performed statistical computations using statistical software (JMP 8, SAS Institute, Inc; Cary, North Carolina) and conducted one-way analysis of variance (ANOVA) at a 5 percent significance level for 


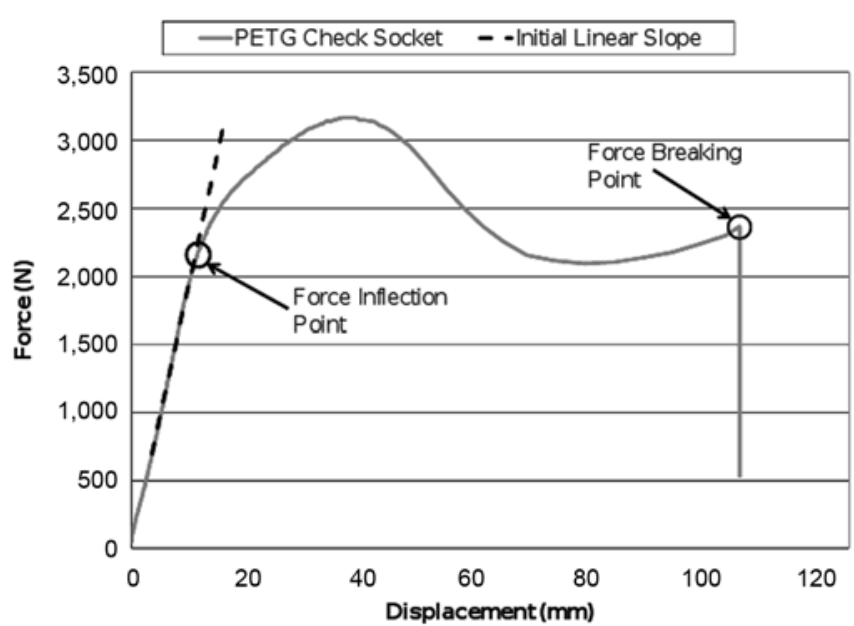

Figure 3.

Sample of force-deflection curve for polyethylene terephthalate glycol (PETG) check socket material. Force inflection point is determined using initial linear slope $\left(R^{2}>0.995\right)$ of curve and engineering definition of yield strength. Force breaking point is also indicated.

each type of analysis. If we detected a significant difference, we conducted an additional comparison analysis using the post hoc Tukey honestly significant difference means comparison test at a 5 percent significance level. This enabled us to detect significant differences between groupings. We also reported relative standard deviation (RSD) values, presenting standard deviations (SDs) as a normalized percentage of the mean. Any alterations to the statistical analysis methodology are indicated within the explanation of the associated data. Figure 4 depicts the analyses conducted.

We do not fully evaluate fatigue failure loads in this article. Testing a single socket of each type from each facility to three million cycles would have taken over 2.5 years of continuous test machine time. We judged this to be impractical and prohibitively expensive. This said, static failure data and simple class tests allowed us to draw some general conclusions, and we sought and applied ways to infer cyclic loading performance for each class of socket. These are discussed with the data from each socket type.

\section{Comparison to Standards}

Since there is no current standard for evaluating prosthetic socket strength, we used loading criteria from ISO 10328, which is used to assess other lower-limb pros-

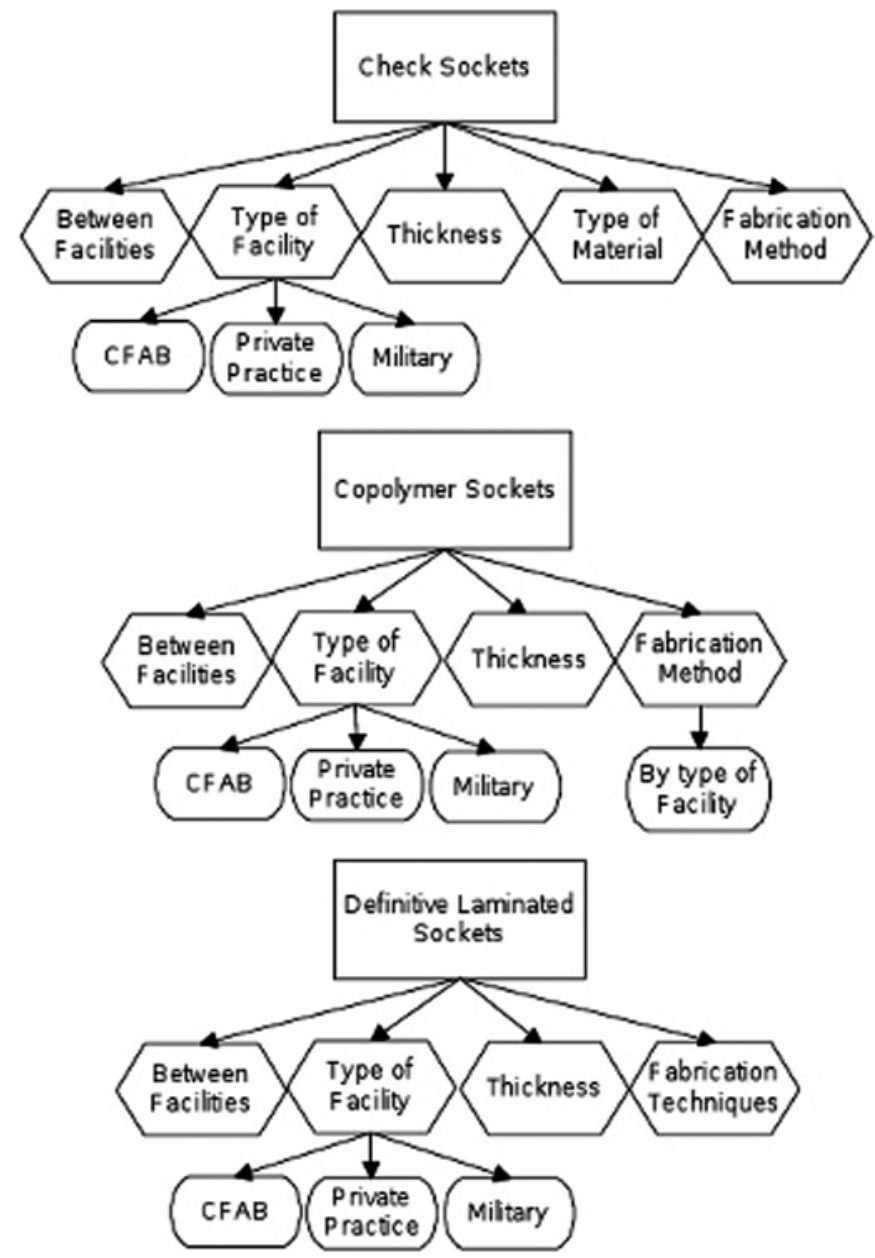

Figure 4.

Illustration of factors analyzed for each type of socket. CFAB = central fabrication.

thetic components, to evaluate the socket's static failure load. We used a selection of anthropometric body mass percentiles to interpolate test loads with ISO 10328. We then compared static failure load values with these values to illustrate the performance of the sockets in relation to the loading likely to be encountered by the general population. Table 1 presents ISO 10328 criteria at different anthropometric population weight percentiles for both ductile and brittle failure modes. Where convenient indicators were not available in the standard, we interpolated values. For this study, deformation before a break indicated ductile failure mode, whereas a brittle failure mode exhibited no or minuscule deformation before a break. Based on an evaluation of the failure modes demonstrated by the samples, we used loads indicated for the ductile failure 
mode in the CS and CP comparisons, while we used the loads for the brittle failure mode in the DL comparisons. Table 1 indicates the static test forces for the ISO 10328 A125 loading criteria.

\section{RESULTS}

\section{Socket Failure Mode}

All sockets failed in the distal cup region with the anterior portion in compression and the posterior portion in tension. Figure 1(b) pictures a static tested CS. All of the CSs but one failed in a ductile mode either by bending or tearing. The CPs typically bent, with 90 percent failing in a ductile mode. DLs all tore at the distal cup region in a brittle failure mode, exhibiting a failure of the fibers, the reinforcement material, and the resin.

\section{Check Sockets}

All nine facilities provided CSs for analysis, and we evaluated a total of 34 . This included sockets from three CFAB facilities, three PP facilities, and three military facilities. Two of the military facilities only provided three of the four requested sockets. Seven of the facilities used the blister fabrication method and two facilities (05 and 09) used a machine-pulled fabrication method. Several materials were used, including PETG (Vivak), ThermoLyn rigid, and Orfitrans Stiff.

Figure 5 presents an initial comparison of each facility's average force inflection point and SD values. The results indicate that CSs from facilities 03, 05, and 09 had the highest average force inflection points. All three facilities used PETG material, and two used machine-

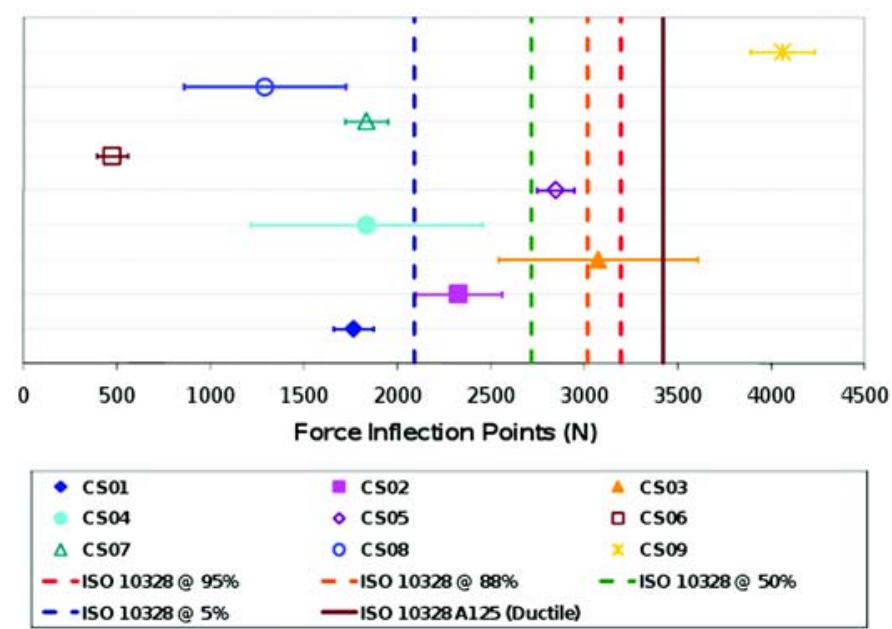

Figure 5.

Check sockets (CSs): mean \pm standard deviation of force inflection point for each facility. International Organization for Standardization (ISO) standard 10328 A125 ductile static test value along with anthropometric test values (95\%, 88\%, 50\%, and $5 \%)$ are indicated with solid line and dotted lines, respectively.

pulled fabrication methods. Facilities 06 and 08 had the lowest average force inflection points. The results also showed that facilities 04 and 08 had the largest variability, with RSDs averaging above 30 percent. The ISO 10328 anthropometric percentiles at 95, 88, 50, and 5 for a ductile failure mode are indicated on the graph with dotted lines, and the ISO 10328 ultimate ductile static test force (passing criterion of 3,421 N) is indicated by the solid line (Figure 5). Only one facility's averages (facility 09) exceeded the ISO 10328 A125 ductile static test force.

Table 1.

International Organization for Standardization (ISO) standard 10328 ultimate static test force condition II for ductile and brittle failures at different anthropometric percentiles. While not explicitly stated in ISO 10328, these values have generally been correlated with patient weight by industry.

\begin{tabular}{cccc}
\hline $\begin{array}{c}\text { Associated Load } \\
\text { Level (kg) }\end{array}$ & $\begin{array}{c}\text { Ultimate Static Test Force } \\
\text { Condition II (ductile failure, N) }\end{array}$ & $\begin{array}{c}\text { Ultimate Static Test Force } \\
\text { Condition II (brittle failure, N) }\end{array}$ & $\begin{array}{c}\text { Anthropometric } \\
\text { Percentile }\end{array}$ \\
\hline $111^{*}$ & $3,196^{*}$ & $4,202^{*}$ & 95 \\
100 & 3,020 & 4,026 & 88 \\
80 & 2,717 & 3,621 & 50 \\
60 & 2,091 & 2,789 & 5 \\
125 & 3,421 & 4,426 & $100^{\dagger}$ \\
\hline
\end{tabular}

*Interpolated values based on 95 percent anthropometric patient weight.

${ }^{\dagger} \mathrm{A} 125$ (ISO 10328). 
Since the facilities' variances were determined to be unequal, we used a Welch ANOVA test (5\% significance level) to statistically compare the facilities. The test detected a difference $(p<0.001)$ between the facilities' force inflection points. Further means analysis on the rank data separated the facilities into five subgroups with slight overlapping. Table 2 displays the results from the comparison test. Facilities with common uppercase letters are not significantly different. Several notable differences included facility 06 producing a lower force inflection point than all of the other facilities except for facility 08, and facility 09 producing a higher force inflection point than all the other facilities except for facilities 03 and 05.

We also analyzed CSs by type of facility: CFAB, PP, and military. We detected no difference in static failure loads ( $p=0.49$ ) between the types of facilities. Figure 6 contains the mean \pm SD values for each type of facility. The highest amount of variability (84\% RSD) occurred between the military facilities.

We conducted analysis within each type of facility. The ANOVA on CFAB facilities indicated a significant difference ( $p=0.001$ ) between the facilities. The mean comparison in Table 3 indicates that CFAB facility 03 had higher force inflection points than the other two (01 and 02). All facilities used blister fabrication method. Facilities 02 and 03 used PETG material, while facility 01 used Orfitrans Stiff material.

Table 2.

Check socket (CS) post hoc Tukey honestly significant difference (HSD) mean comparison (5\% significance level) for all facilities. Facilities with common uppercase letters are not significantly different.

\begin{tabular}{lcccccc}
\hline Facility & \multicolumn{3}{c}{ Tukey HSD Comparison } & $\begin{array}{c}\text { Mean Force } \\
\text { Inflection } \\
\text { Point (N) }\end{array}$ \\
\hline CS09 & A & - & - & - & - & 4,064 \\
CS03 & A & B & - & - & - & 3,075 \\
CS05 & A & B & - & - & - & 2,848 \\
CS02 & - & B & C & - & - & 2,328 \\
CS04 & - & - & C & D & - & 1,834 \\
CS07 & - & - & C & D & - & 1,834 \\
CS01 & - & - & C & D & - & 1,765 \\
CS08 & - & - & - & D & E & 1,290 \\
CS06 & - & - & - & - & E & 474 \\
\hline \hline
\end{tabular}

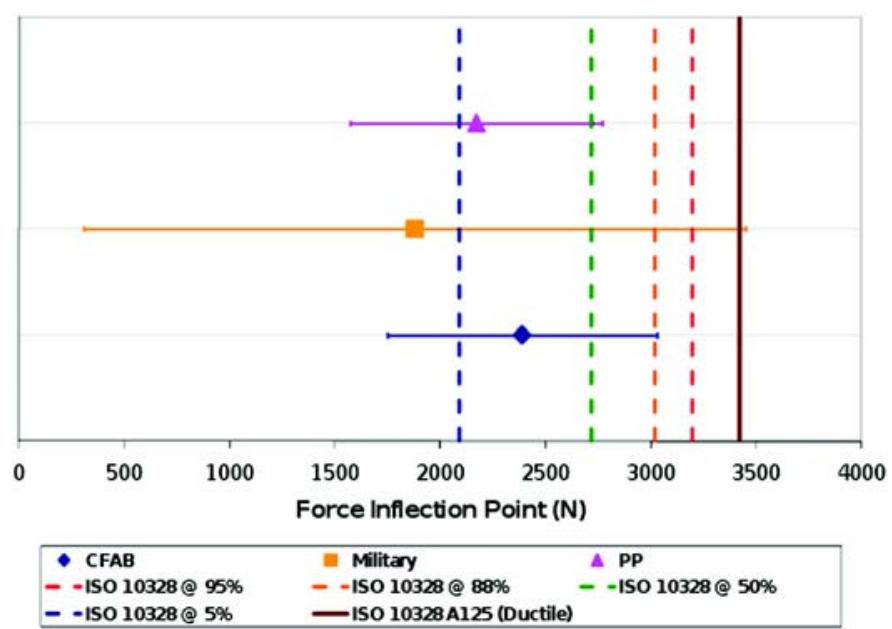

Figure 6.

Check sockets mean \pm standard deviation comparison for type of facilities (central fabrication [CFAB], private practice [PP], and military). International Organization for Standardization (ISO) standard 10328 A125 ductile static test value along with anthropometric test values $(95 \%, 88 \%, 50 \%$, and $5 \%)$ are indicated with solid line and dotted lines, respectively.

Since the variance for the PP facilities was unequal, we conducted a Welch ANOVA test (5\% significance level) that indicated a difference $(p<0.001)$ between the facilities. The means comparison in Table 3 indicates that facility 05 had higher force inflection values than the other two (04 and 07). Facility 05 used machine-pulled fabrication methods while the other two used blister fabrication methods, with similar distal socket thicknesses. All three facilities constructed sockets with PETG material.

Analysis of the military facilities indicated a significant difference $(p<0.001)$ between the facilities. The means comparison in Table 3 indicates that all three facilities exhibited different strengths. In fact, military facilities provided sockets with both the highest and lowest static failure values seen for the CSs. Facility 09 CSs had the highest force inflection points and facility 06 CSs had the lowest force inflection points. CSs from facilities 08 and 09 were constructed with the same type of material (PETG), while facility 06 used ThermoLyn rigid material. Facilities 06 and 08 used blister fabrication methods while facility 09 used a socket pulling machine. Facility 09 produced, on average, the thickest sockets out of the three facilities.

To evaluate the factors contributing to CS material performance, we conducted a correlation analysis between 
JRRD, Volume 49, Number 3, 2012

Table 3.

Post hoc Tukey honestly significant difference (HSD) means comparison on check sockets (CSs) within each type of facility: central fabrication (CFAB), private practice (PP), and military. Facilities with common uppercase letters are not significantly different.

\begin{tabular}{|c|c|c|c|c|c|c|c|c|c|c|c|c|}
\hline \multicolumn{4}{|c|}{ CFAB } & \multicolumn{4}{|c|}{$\mathbf{P P}$} & \multicolumn{5}{|c|}{ Military } \\
\hline Facility & $\begin{array}{l}\text { Tuk } \\
\text { Con }\end{array}$ & $\begin{array}{l}\text { ISD } \\
\text { ison }\end{array}$ & $\begin{array}{c}\text { Mean Force } \\
\text { Inflection } \\
\text { Point (N) }\end{array}$ & Facility & $\begin{array}{l}\text { Tuk } \\
\text { Con }\end{array}$ & $\begin{array}{l}\text { HSD } \\
\text { ison }\end{array}$ & $\begin{array}{c}\text { Mean Force } \\
\text { Inflection } \\
\text { Point (N) }\end{array}$ & Facility & & $\begin{array}{l}\text { key I } \\
\text { mpa }\end{array}$ & & $\begin{array}{l}\text { Mean Force } \\
\text { Inflection } \\
\text { Point (N) }\end{array}$ \\
\hline CS03 & A & - & 3,075 & CS05 & A & - & 2,848 & CS09 & A & - & - & 4,064 \\
\hline CS02 & - & B & 2,328 & CS04 & - & B & 1,834 & CS08 & - & B & - & 1,290 \\
\hline CS01 & - & B & 1,765 & CS07 & - & B & 1,834 & CS06 & - & - & C & 474 \\
\hline
\end{tabular}

the force inflection values and distal socket thicknesses for each material type. Figure 7 shows a graphical relationship. We found a correlation between the force inflection points and distal socket thickness for PETG material $(r=0.92)$. Since ThermoLyn rigid and Orfitrans Stiff materials were provided by only one facility each, we did not analyze correlation with thickness. However, sockets made from ThermoLyn rigid and Orfitrans Stiff appear to follow the same thickness trend line and were found to have similar mechanical properties in another study [10]. Figure 7 illustrates that sockets made from ThermoLyn rigid and Orfitrans Stiff materials required thicker distal socket walls to produce inflection forces comparable with sockets made from PETG materials. Table 4 lists the number of sockets constructed from each type of material. Four PETG CSs were constructed with medial lock holes that we did not specify in the original fabrication instructions. Therefore, we constructed an additional

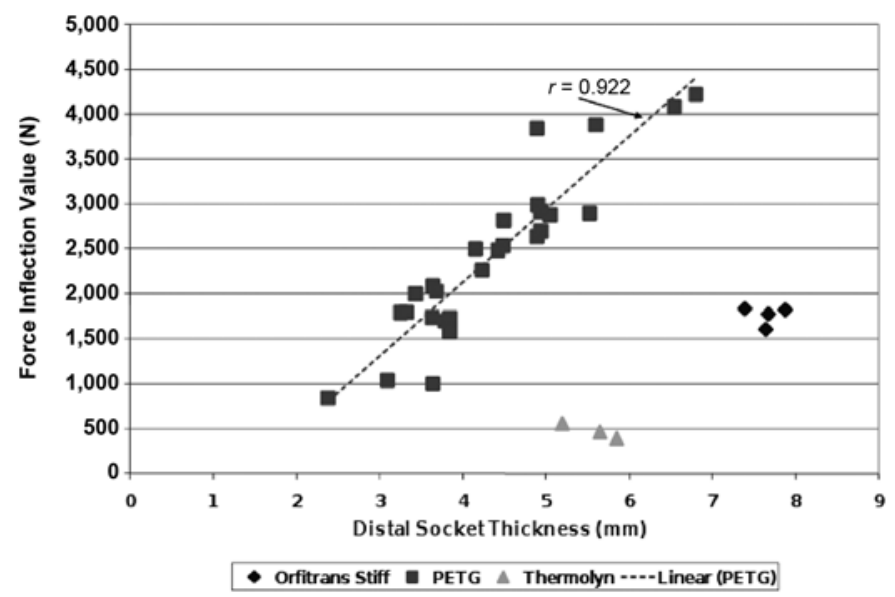

Figure 7.

Check socket force inflection point versus distal thicknesses for check sockets grouped by material type. PETG = polyethylene terephthalate glycol.
ANOVA confirming no detectable difference $(p=0.99)$ between samples caused by this alteration in design, indicating that the stress field peaks primarily responsible for the structural failure of these sockets were not affected by these modifications. Statistical analysis revealed a significant difference (Welch ANOVA, $p<0.001$ ) between the three types of material. The means comparison (Table 4) indicated that the ThermoLyn rigid sockets had lower force inflection points than PETG material.

Ideally, for patient safety, a ductile failure mode with compression at the distal plane is preferred. This assures that the patient has some warning of imminent failure and that the patient's residual limb is not exposed to fracture surfaces or stress concentrations caused by the failure. All but one CS failed in a ductile mode. All sockets showed signs of either compression along the socket's anterior neck curvature or of the distal plane at the location of the four-hole attachment plate. Therefore, we conducted an additional analysis on the break energy. The break energy refers to the energy absorbed by the socket at the point of breaking (failure). We observed a correlation ( $r=0.81$ ) between distal (cup) thickness and the PETG break energy (Figure 8). We did not conduct this

Table 4.

Check socket material analysis: number of sockets constructed by each type of material and Tukey honestly significant difference (HSD) mean comparison. Materials with common uppercase letters are not significantly different.

\begin{tabular}{lcccc}
\hline \multicolumn{1}{c}{ Material } & $\begin{array}{c}\text { No. of } \\
\text { Sockets }\end{array}$ & $\begin{array}{c}\text { Tukey HSD } \\
\text { Comparison }\end{array}$ & $\begin{array}{c}\text { Mean Force } \\
\text { Inflection } \\
\text { Point (N) }\end{array}$ \\
\hline PETG & 27 & A & - & 2,408 \\
Orfitrans Stiff & 4 & A & B & 1,765 \\
ThermoLyn & 3 & - & B & 474 \\
rigid & & & & \\
\hline PETG = polyethylene terephthalate glycol. \\
\hline
\end{tabular}




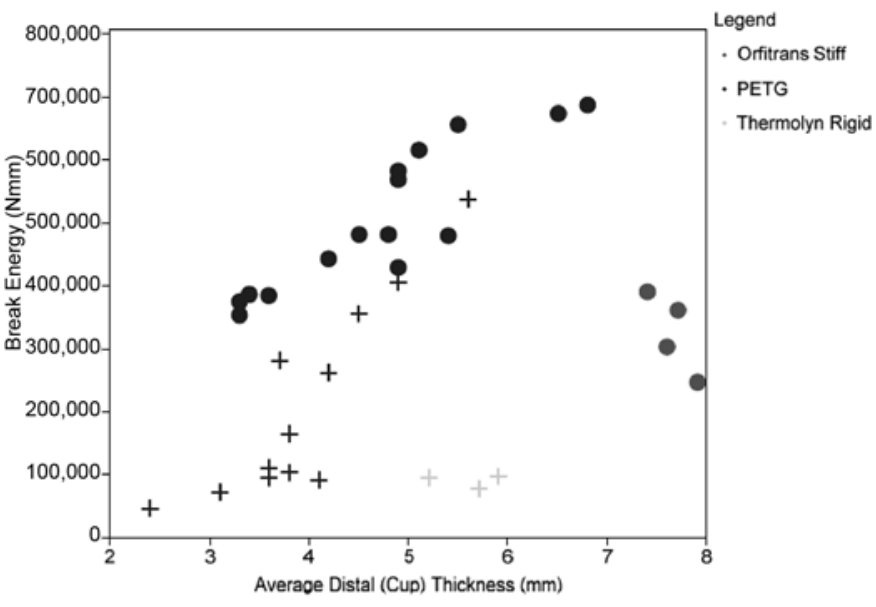

Figure 8.

Check socket's distal thickness versus break energy. Location of ductile compression is indicated either at socket's neck curvature $(+)$ or at distal plane where distal adapter is attached $(\bullet)$. Figure 1(a) illustrates socket location of distal cup, neck curvature, and distal plane. PETG = polyethylene terephthalate glycol.

analysis on the other materials because of the limited number of sockets; however, Orfitrans Stiff and ThermoLyn rigid appear to require greater thicknesses to achieve an equivalent level of break energy. Additionally, PETG sockets with distal thicknesses greater than $5 \mathrm{~mm}$ generally had more favorable outcomes (higher break energy with compression in the distal plane).

Two types of fabrication methods were used to construct the CSs: blister and machine-pulled. A comparison of these fabrication methods $(p<0.001)$ indicates that the machine-pulled sockets (mean $=3,368 \mathrm{~N}$ ) had higher force inflection points than the blister-formed sockets (mean $=1,849 \mathrm{~N})$. The machine-pulled facilities used PETG and produced the least amount of variability with a RSD range of 3 to 4 percent. Table 5 summarizes the average force inflection point, force inflection SD, force inflection RSD, fabrication method, and type of material.

As mentioned earlier, cyclic loading testing was not practical in a study of this scale. However, considering the requirements for cyclic fatigue in ISO 10328 and examining the data in Table 5 allows us to draw some general conclusions. The cyclic loading test in ISO 10328 consists of 3 million cycles over a fixed load range, followed by a static proof test. The level of this static proof test for A125 loading in condition II is 2,263 N. This value exceeds the static inflection point of most of the CSs in the test. For this reason, it is possible to conclude that most CSs would not comply with ISO 10328 cyclic loading criteria at the A125 level.

\section{Copolymer Sockets}

Eight facilities provided CPs for analysis. We tested a total of 31. This included sockets from three CFAB facilities, three PP facilities, and two military facilities. One military facility does not fabricate CPs as a normal practice; therefore, we omitted it from this portion of the study. One facility provided only three sockets instead of the requested four sockets. Four of the facilities used a blister fabrication method. Two facilities (05 and 09) used a machine-pulled fabrication method, and two facilities (02 and 08) used a drape fabrication method.

Figure 9 shows a graphical depiction of the mean \pm SD of the inflection loads for each facility's copolymer

Table 5.

Summary table for check sockets (CSs).

\begin{tabular}{|c|c|c|c|c|c|c|}
\hline Facility & Type of Facility & $\begin{array}{c}\text { Mean Force } \\
\text { Inflection Point }(\mathrm{N})\end{array}$ & $\operatorname{SD}( \pm \mathbf{N})$ & $\begin{array}{c}\text { Relative SD } \\
( \pm \%)\end{array}$ & Material & $\begin{array}{c}\text { Fabrication } \\
\text { Method }\end{array}$ \\
\hline CS01 & CFAB & 1,765 & 105 & 86 & Orfitrans Stiff & Blister \\
\hline CS02 & CFAB & 2,328 & 230 & 10 & PETG & Blister \\
\hline CS03 & CFAB & 3,075 & 534 & 17 & PETG & Blister \\
\hline CS04 & PP & 1,834 & 619 & 34 & PETG & Blister \\
\hline CS05 & $\mathrm{PP}$ & 2,848 & 100 & 3 & PETG & Machine-Pulled \\
\hline CS07 & $\mathrm{PP}$ & 1,834 & 114 & 6 & PETG & Blister \\
\hline CS08 & Military & 1,290 & 434 & 34 & PETG & Blister \\
\hline CS09 & Military & 4,064 & 171 & 4 & PETG & Machine-Pulled \\
\hline
\end{tabular}




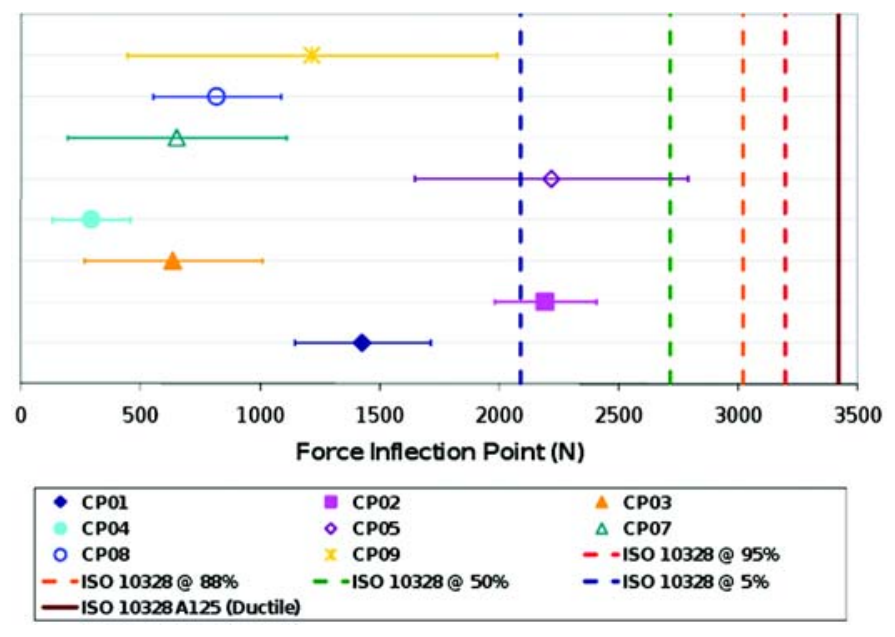

Figure 9.

Mean \pm standard deviation of force inflection point for each facility's copolymer sockets (CPs). International Organization for Standardization (ISO) standard 10328 A125 ductile static test value along with anthropometric test values (95\%, 88\%, $50 \%$, and $5 \%$ ) are indicated with solid line and dotted lines, respectively.

sockets. The results indicate that CPs from facilities 02 and 05 had the highest average force inflection points. In contrast, facilities $03,04,07$, and 08 had the lowest average force inflection points. Facilities 03, 04, 07, and 09 had the highest amount of variability, with RSDs ranging from 56 to 70 percent. The ISO 10328 A125 passing force for ductile static testing and anthropometric percentiles for a ductile failure mode are indicted in Figure 9. None of the facilities' averages exceeded the ISO 10328 at the 50 percent anthropometric level; thus, all sockets failed the ISO 10328 A125 static test for ductile materials. Only two facilities (02 and 05) had sockets surpass ISO 10328 loading criteria at the 5 percent anthropometric level.

In analyzing the differences between facilities, the ANOVA indicated a difference $(p<0.0001)$ between facilities regarding the force inflection points. Table 6 illustrates means comparisons. Facility 04 generated lower force inflection points than facilities 05, 02, and 01 . Facilities 02 and 05 used drape and machine-pulled methods, respectively. Facilities 01 and 04 used the blister fabrication method. On average, facility 03 and 04 sockets were the thinnest distally and had the lowest average force inflection values.

We also analyzed CPs by fabrication method: blister (five facilities), drape (two facilities), and machinepulled (two facilities). Statistical analysis indicated a sig-
Table 6.

Copolymer socket (CP) post hoc Tukey honestly significant difference (HSD) mean comparison (95\% criteria level) for all facilities. Facilities with common uppercase letters are not significantly different.

\begin{tabular}{lcccc}
\hline Facility & Tukey HSD Comparison & $\begin{array}{c}\text { Mean Force } \\
\text { Inflection } \\
\text { Point (N) }\end{array}$ \\
\hline CP05 & A & - & - & 2,218 \\
CP02 & A & - & - & 2,192 \\
CP01 & A & B & - & 1,428 \\
CP09 & A & B & C & 1,217 \\
CP08 & - & B & C & 818 \\
CP07 & - & B & C & 653 \\
CP03 & - & B & C & 636 \\
CP04 & - & - & C & 293 \\
\hline \hline
\end{tabular}

nificant difference ( $p=0.003$ ) in the load capacity of sockets manufactured by different fabrication methods. Further analysis (Table 7) indicates that the blister method produced lower load capacity than the other two methods. We found no detectable difference between the machine-pulled sockets and drape-formed sockets. The machine-pulled sockets had the least amount of variability (RSD $=45 \%$ ) and produced, on average, thicker sockets.

To further understand the effects of fabrication, we investigated the effect of distal socket thickness on force inflection points for all data. Since all sockets were constructed with copolymer material, we also evaluated data for all sockets as a group. The overall correlation coefficient between force inflection points and average distal socket thickness was 0.88 when we lumped together all data for all fabrication methods. We observed a strong correlation for drape $(r=0.96)$ and machine-pulled fabrication $(r=0.89)$. A less significant correlation was present for blister fabrication $(r=0.71)$. Figure 10 displays the correlation categorized by fabrication method.

Table 7.

Copolymer socket fabrication method analysis: number of sockets constructed by each type of method and Tukey honestly significant different (HSD) mean comparison. Methods with common uppercase letters are not significantly different.

\begin{tabular}{lcccc}
\hline Method & $\begin{array}{c}\text { No. of } \\
\text { Sockets }\end{array}$ & $\begin{array}{c}\text { Tukey HSD } \\
\text { Comparison }\end{array}$ & $\begin{array}{c}\text { Mean Force } \\
\text { Inflection } \\
\text { Point (N) }\end{array}$ \\
\hline Machine-Pulled & 7 & $\mathrm{~A}$ & - & 1,789 \\
Drape & 8 & $\mathrm{~A}$ & - & 1,505 \\
Blister & 16 & - & $\mathrm{B}$ & 7,53 \\
\hline \hline
\end{tabular}




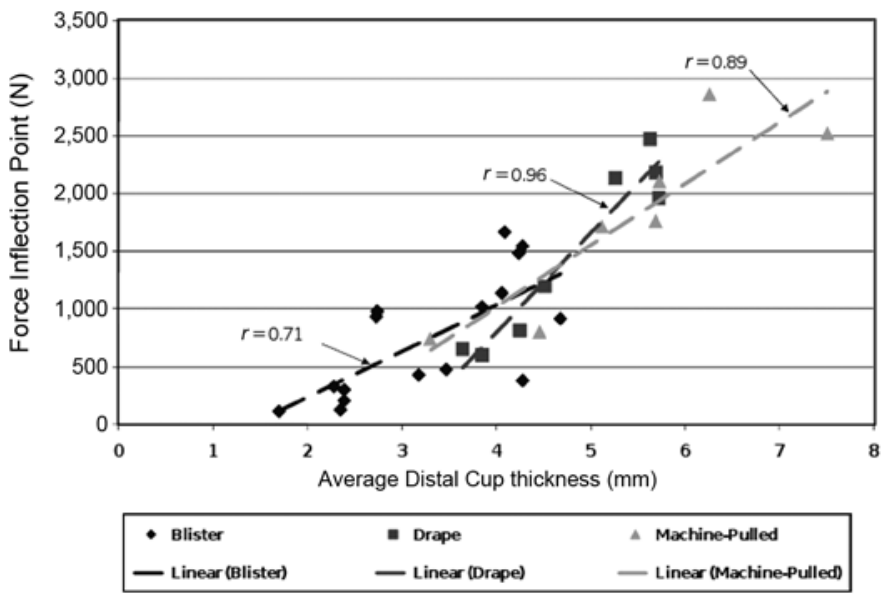

Figure 10.

Correlation between force inflection points and average distal socket thicknesses for copolymer sockets categorized by fabrication method.

A majority of the CPs failed in a ductile mode with signs of either compression at the socket's anterior neck curvature or compression at the distal plane (adapter attachment site). We observed a correlation ( $r=0.89)$ between break energy and distal (cup) thickness (Figure 11). We also observed an additional trend (correlation $r=$ 0.73) between break energy and the ratio of the distal plane thickness to the distal cup thickness (Figure 11).

We also analyzed CPs by type of facility: CFAB, PP, and military. Since we previously determined a significant difference for the fabrication methods, we conducted this analysis on each type of fabrication method. The blister fabrication method was the most common method and was used by both CFAB and PP facilities. Statistical analysis detected a difference $(p=0.02)$ between the types of facilities that used the blister method. As shown in Table 8, PP facilities had lower force inflection points compared with CFAB facilities. For drape fabrication method, which included military and CFAB facilities, statistical analysis $(p<0.002)$ detected that CFAB facility sockets had higher force inflection points than military facility sockets (Table 8). The final analysis regarding types of facilities was between PP and military facilities that used machine-pulled methods. We detected no significant difference $(p=0.10)$ between the two types of facilities. Table 8 displays the average values for these two types of facilities.

We conducted analysis within each type of facility. The statistical analysis $(p<0.002)$ and means compari-

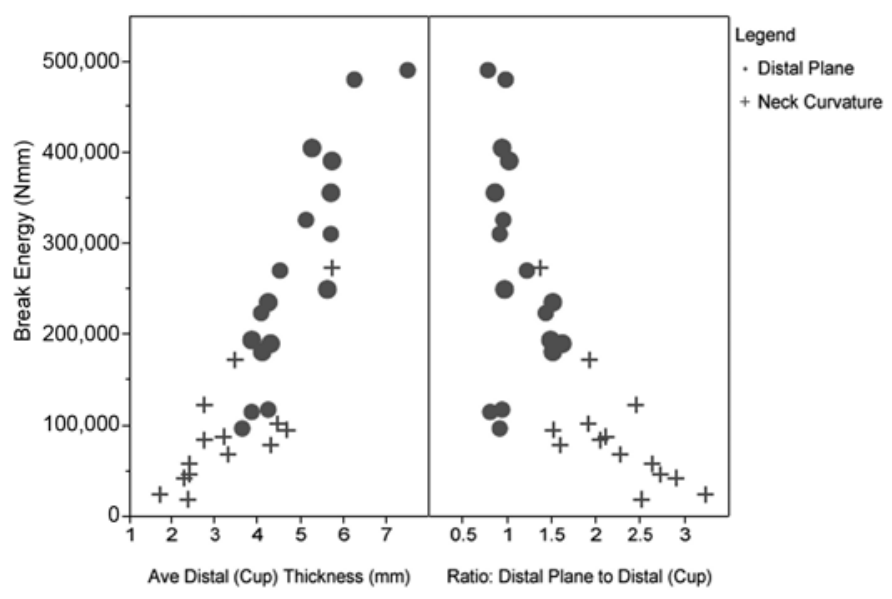

Figure 11.

Copolymer sockets: breaking energy versus average distal (cup) thickness and break energy versus ratio between distal plane thickness and distal (cup) thickness. Location of ductile compression is indicated either at socket's neck curvature $(+)$ or at distal plane where distal adapter is attached ( $\bullet$ ). Figure 1(a) illustrates socket location of distal cup, neck curvature, and distal plane. Ave = average.

son on CFAB facilities revealed that they were all significantly different from each other (Table 9). Facility 02 had the highest force inflection points and used the drape fabrication method. The other two facilities used the blister fabrication method. Facility 03 had the thinnest distal socket thicknesses and the greatest amount of force inflection variability (RSD $=59 \%$ ), while facility 02 had the thickest distal socket thicknesses and the least amount of force inflection variability (RSD $=10 \%$ ).

For the PP facilities, statistical analysis $(p<0.003)$ and means comparison (Table 9) indicated that PP facility 05 had higher force inflection values than the other two (04 and 07). We found no significant difference between facilities 04 and 07 . Facility 05 used a machinepulled fabrication method while the other two used a blister fabrication method. Both facility 04 and facility 07 had higher variability between sockets than facility 05 , with RSDs of 56 and 70 percent, respectively. The distal socket thicknesses were also thinner for these sockets.

Regarding the military facilities, we found no significant difference between the two $(p=0.37)$. Table 9 illustrates average values for the facilities' force inflection points. Facility 09 contained a higher variability (RSD = $64 \%)$ than facility $08($ RSD $=33 \%)$. Facility 08 used the drape fabrication method with thinner distal socket 
JRRD, Volume 49, Number 3, 2012

Table 8.

Copolymer socket type of facility analysis by fabrication method: number of sockets constructed by each fabrication method and Tukey honestly significant difference (HSD) mean comparison. Facility types with common uppercase letters are not significantly different.

\begin{tabular}{|c|c|c|c|c|c|}
\hline \multirow{2}{*}{$\begin{array}{l}\text { Fabrication Method } \\
\text { Blister }\end{array}$} & \multirow{2}{*}{$\begin{array}{c}\text { Type of Facility } \\
\text { CFAB }\end{array}$} & \multirow{2}{*}{$\begin{array}{c}\text { No. of Sockets } \\
8\end{array}$} & \multicolumn{2}{|c|}{ Tukey HSD Comparison } & \multirow{2}{*}{$\begin{array}{c}\begin{array}{c}\text { Mean Force } \\
\text { Inflection Point (N) }\end{array} \\
1,032\end{array}$} \\
\hline & & & $\mathrm{A}$ & - & \\
\hline & PP & 8 & - & $\mathrm{B}$ & 473 \\
\hline \multirow[t]{2}{*}{ Drape } & CFAB & 4 & $\mathrm{C}$ & 一 & 2,192 \\
\hline & Military & 4 & - & $\mathrm{D}$ & 818 \\
\hline \multirow[t]{2}{*}{ Machine-Pulled } & $\mathrm{PP}$ & 4 & $\mathrm{E}$ & - & 2,218 \\
\hline & Military & 3 & $\mathrm{E}$ & - & 1,217 \\
\hline
\end{tabular}

CFAB = central fabrication, $\mathrm{PP}$ = private practice.

Table 9.

Post hoc Tukey honestly significant difference (HSD) means comparison on copolymer sockets (CPs) within each type of facility: central fabrication (CFAB), private practice (PP), and military. Facility types with common uppercase letters are not significantly different.

\begin{tabular}{|c|c|c|c|c|c|c|c|c|c|c|c|}
\hline \multicolumn{5}{|c|}{ CFAB } & \multicolumn{4}{|c|}{$\mathbf{P P}$} & \multicolumn{3}{|c|}{ Military } \\
\hline Facility & & $\begin{array}{l}\text { uke } \\
\text { HSD } \\
\text { ipar }\end{array}$ & & $\begin{array}{l}\text { Mean Force } \\
\text { Inflection } \\
\text { Point (N) }\end{array}$ & Facility & & $\begin{array}{l}\text { ey } \\
\text { D } \\
\text { Irison }\end{array}$ & $\begin{array}{l}\text { Mean Force } \\
\text { Inflection } \\
\text { Point (N) }\end{array}$ & Facility & $\begin{array}{c}\text { Tukey } \\
\text { HSD } \\
\text { Comparison }\end{array}$ & $\begin{array}{l}\text { Mean Force } \\
\text { Inflection } \\
\text { Point (N) }\end{array}$ \\
\hline$\overline{\mathrm{CP} 02}$ & $\mathrm{~A}$ & - & - & 2,192 & CP05 & $\mathrm{A}$ & - & 2,218 & CP09 & $\mathrm{A}$ & 1,217 \\
\hline СР01 & - & B & - & 1,428 & СР07 & - & B & 653 & СР08 & A & 818 \\
\hline СР03 & - & - & $\mathrm{C}$ & 636 & СР04 & - & B & 293 & - & - & - \\
\hline
\end{tabular}

thicknesses, while facility 09 used the machine-pulled fabrication method with thicker distal socket thicknesses. Table 10 summarizes the average force inflection point, force inflection SD, force inflection RSD, and fabrication method for the CPs.

As mentioned earlier, the static proof test component of the cyclic loading test for A125 loading in condition II is $2,263 \mathrm{~N}$. This value exceeds the static inflection point of nearly all of the CPs in the test. Interestingly enough, one of the thicker sockets received from facility 05 , a facility that uses a socket-pulling machine, was able to be tested and in fact passed 3 million cycles at the A125 level. While most CPs probably would not comply with ISO 10328 cyclic loading criteria at the A125 level for this reason, with care, CPs can possibly meet this criterion with careful attention to material thickness.

\section{Definitive Laminated Sockets}

All nine facilities provided DLs, for a total of 33. Two military facilities only supplied three DLs, and another one was ruined during the test setup process. We classified the DLs into three categories according to known fabrication techniques: carbon lamination with non-pigmented resin (17 sockets), carbon lamination with pigmented resin (12 sockets), and nyglass (4 sockets). We analyzed DLs by evaluating the force compression point indicated either by a deformation peak or a plateau change in slope. In many cases, the force compression point was the same as a force inflection point. Force compression points were not correlated with distal socket thickness ( $r=0.33$ ).

The first analysis compared individual facilities. Figure 12 presents a graphical depiction of the mean \pm SD of the force compression point for each facility. The ISO 10328 A125 brittle failure mode static test criterion $(4,426 \mathrm{~N})$ and the anthropometric percentiles at 95, 88, 50 , and 5 percent are indicated on the graph with a solid line and dotted lines, respectively. The results show that DLs from facilities 01, 03, and 09 had the highest averages. The results also indicate that facilities 05, 06, 07, and 08 had the highest amount of variability, with RSD values ranging from approximately 21 to 46 percent. Facilities 01, 03, 06, and 09 produced averages at or above the anthropometric 95 percent ISO 10328 level; however, the SD for facility 06 extends below the anthropometric 50 percent ISO 10328 level. Two facilities, 04 and 08 , had variances below the anthropometric 5 percent ISO 10328 level. The averages of five facilities 
Table 10.

Summary table for copolymer socket (CP).

\begin{tabular}{|c|c|c|c|c|c|}
\hline Facility & Type of Facility & $\begin{array}{c}\text { Ave Force } \\
\text { Inflection Points (N) }\end{array}$ & $\operatorname{SD}( \pm N)$ & Relative SD $( \pm \%)$ & Method \\
\hline CP01 & CFAB & 1,428 & 286 & 20 & Blister \\
\hline СР02 & CFAB & 2,192 & 213 & 10 & Drape \\
\hline СР03 & CFAB & 636 & 373 & 59 & Blister \\
\hline СР07 & $\mathrm{PP}$ & 653 & 459 & 70 & Blister \\
\hline СР08 & Military & 818 & 267 & 33 & Drape \\
\hline СР09 & Military & 1,217 & 773 & 64 & Machine-Pulled \\
\hline
\end{tabular}

below the solid line $(02,04,05,07$, and 08$)$ failed to pass the A125 ISO 10328 brittle static test force.

In comparing facilities, we detected a significant difference $(p<0.007)$ between them regarding the force compression points. Further analysis indicates a separation between facilities (Table 11), with facility 03 having a higher load capacity than facilities 02, 04, and 08.

We analyzed DLs according to facility type: CFAB, PP, and military. We detected no significant difference ( $p=$ 0.07 ) between the types of facilities. Figure 13 shows the mean \pm SD values for each type of facility. CFAB facility

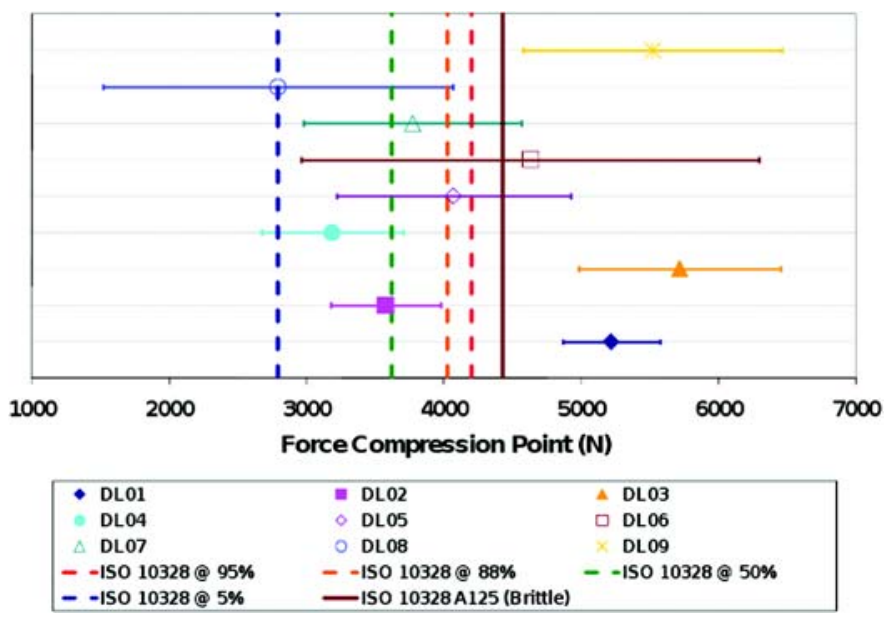

Figure 12.

Mean \pm standard deviation of force compression point for each facility's definitive laminated sockets (DLs). International Organization for Standardization (ISO) standard 10328 A125 brittle static test value along with anthropometric test values $(95 \%$, $88 \%, 50 \%$, and $5 \%$ ) are indicated with solid line and dotted lines, respectively.
DLs had force compression values ranging above the anthropometric 50 percent ISO 10328 level. The SD for the PP DLs extended below the anthropometric 50 percent ISO 10328 level, and the SD for the military DLs extended below the anthropometric 5 percent ISO 10328 level.

We conducted comparisons within each type of facility. Statistical analysis on CFAB facilities $(p<0.007)$ indicated that CFAB facility 02 had lower force inflection points than the other two (01 and 03). Facilities 01 and 03 were not significantly different. Statistical analysis on military facilities detected no difference $(p=0.11)$ between the facilities. Facility 08 's variability may be a factor of socket fit, since some of the sockets were either

Table 11.

Definitive laminated sockets (DLs) post hoc Tukey honestly significant difference (HSD) means comparison analysis (95\% criteria level) for all facilities. Facilities with common uppercase letters are not significantly different.

\begin{tabular}{lllllc}
\hline Facility & \multicolumn{2}{l}{ Tukey HSD Comparison } & $\begin{array}{c}\text { Mean } \\
\text { Compression } \\
\text { Force (N) }\end{array}$ \\
\hline DL03 & A & - & - & - & 5,713 \\
DL09 & A & B & - & - & 5,519 \\
DL01 & A & B & C & - & 5,218 \\
DL06 & A & B & C & D & 4,629 \\
DL05 & A & B & C & D & 4,068 \\
DL07 & A & B & C & D & 3,769 \\
DL02 & - & B & C & D & 3,575 \\
DL04 & - & - & C & D & 3,187 \\
DL08 & - & - & - & D & 2,791 \\
\hline
\end{tabular}


JRRD, Volume 49, Number 3, 2012

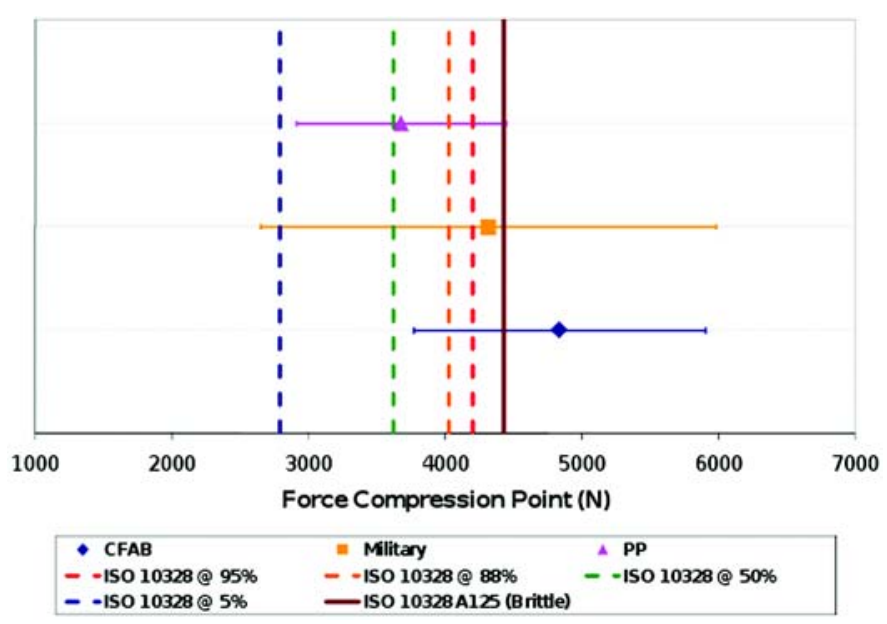

Figure 13.

Definitive laminated sockets: mean \pm standard deviation comparison for type of facilities (central fabrication [CFAB], private practice [PP], and military). International Organization for Standardization (ISO) standard 10328 A125 brittle static test value along with anthropometric test values (95\%, 88\%, 50\%, and $5 \%)$ are indicated with solid line and dotted lines, respectively.

undersized or oversized compared with the test fixture. As part of normal practice, facility $09(\mathrm{RSD}=17 \%)$ does not fabricate DLs in-house; therefore, the sockets were constructed by their usual CFAB facility. We detected no significant difference ( $p=0.28$ ) between the PP facilities. Table 12 presents the within-facility mean comparison results.

Table 13 summarizes the average force compression point, force compression SD, force compression RSD, and fabrication technique for the DLs. We determined no significant difference $(p=0.17)$ between the fabrication techniques.

A quick review of Table 13 reveals that the average force compression point for laminated sockets for all suppliers to the study exceeded the 2,263 $\mathrm{N}$ static proof test required by ISO 10328 condition II cyclic testing. As stated earlier, the performance of fatigue testing on a large number of samples was not practical. Also, we were short three DLs because of the limited number of sockets supplied and accidental damage to one socket. Retrospective evaluation of the initial data used to design the overall study showed that the mechanical properties of the sockets manufactured at the in-house CFAB facility were comparable with the sockets that had been obtained from other CFAB facilities. For this reason, in this one case, we ordered a DL from the in-house CFAB facility using the same computer model. We directed the CFAB facility to use the same lay-up and process as they used for the sockets in the pilot study and did not inform them of the type of testing to be performed on the socket. This socket completed a full cyclic loading test and the final static proof test without signs of wear. We believe that this is probably indicative of the fatigue performance that can be expected from most DLs being delivered to patients today.

\section{DISCUSSION}

\section{Limitations}

The goal of this study was to summarize the performance of the current state-of-the-art for an entire industry. In a study of this type, testing all of the facets of a process is difficult or perhaps impossible. It is therefore necessary to hold some variables constant. There are also inevitable variances in the protocol. Both of these factors can lead to possible directions for future study. We believe that the protocol design choices made for this study resulted in a reasonable balance between the breadth of information evaluated and the feasibility of the study. This said, there were limitations that should be pointed out and the results of this study may point to some of these limitations as directions for future research.

This study relied heavily on the use of the test procedures described in ISO 10328. This standard does not currently apply to lower-limb sockets. However, a necessity of the study was to find a common test procedure that could serve as an indicator of socket performance. Applying the standard used to evaluate nearly all of the components to which a socket is attached was a natural choice. Further, there is some historical precedent for the use of ISO 10328 [4,6,11-12] and continuing with this trend allows for comparisons between this study and those that preceded it.

This study evaluated sockets of a single geometry. This was necessary for using statistical analysis on the resulting data set. Even with a single geometry, the study required testing 98 sockets from nine different providers to assure that a meaningful level of statistical convergence would be obtained. This cost many man-hours of work and considerable financial expense. A more general study could have been designed but could easily have required many hundreds, or perhaps even more than a thousand, 
Table 12.

Definitive laminated sockets (DLs) post hoc Tukey honestly significant difference (HSD) mean comparison (95\% criteria level) within each type of facility. Facilities with common uppercase letters are not significantly different.

\begin{tabular}{|c|c|c|c|c|c|c|c|c|c|}
\hline \multicolumn{4}{|c|}{ CFAB } & \multicolumn{3}{|c|}{ PP } & \multicolumn{3}{|c|}{ Military } \\
\hline Facility & $\begin{array}{r}\mathrm{T} \\
1 \\
\text { Con }\end{array}$ & ison & $\begin{array}{c}\text { Compression } \\
\text { Force (N) }\end{array}$ & Facility & $\begin{array}{c}\text { Tukey } \\
\text { HSD } \\
\text { Comparison }\end{array}$ & $\begin{array}{c}\text { Compression } \\
\text { Force (N) }\end{array}$ & Facility & $\begin{array}{l}\text { Tukey HSD } \\
\text { Comparison }\end{array}$ & $\begin{array}{c}\text { Compression } \\
\text { Force (N) }\end{array}$ \\
\hline DL01 & A & - & 5,218 & DL07 & A & 3,769 & DL06 & A & 4,629 \\
\hline DL02 & - & B & 3,575 & DL04 & A & 3,187 & DL08 & A & 2,791 \\
\hline
\end{tabular}

Table 13.

Summary table for definitive laminated socket (DL).

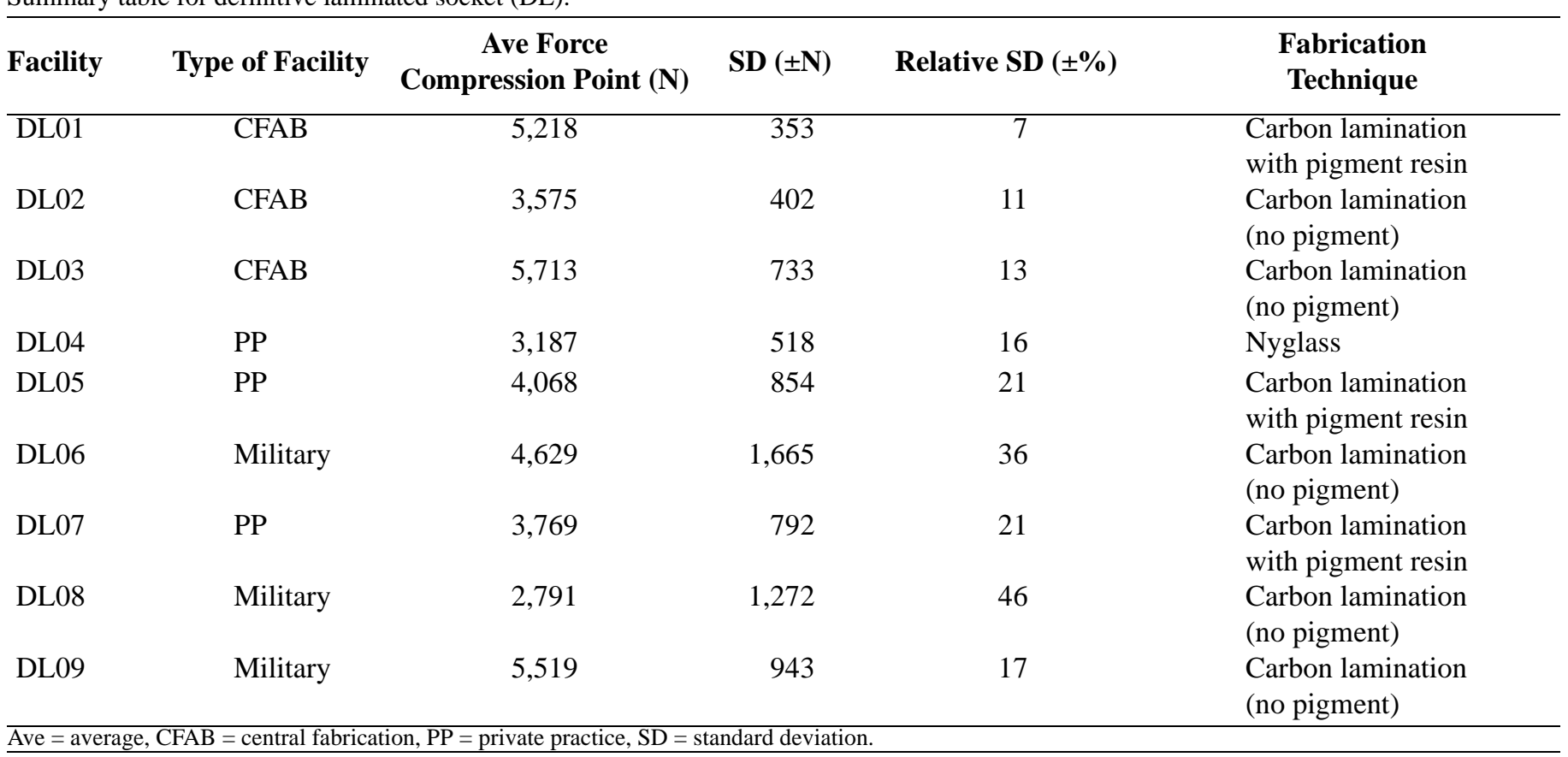

sockets to get the same level of convergence. The cost and time needed to achieve this goal would have been prohibitive.

Another constraint was using a 98th percentile male loading profile and a commensurate geometry. We made this choice simply because it maximally stressed the design practices of the current state-of-the-art. While the size of the socket was obviously known to all of the providers, it was not apparent that this aspect of the "patient's" needs was taken into account by many of the socket providers. Further, we are not aware of any inquiries from any of the providers regarding the weight or activity level of the patients. This aspect in the process probably bears some level of evaluation.
This study used CAD data as the method of communicating a shape to all of the providers. One possibility would have been to send plaster casts or some other physical model. However, this would have added the variability of the model fabrication process into the equation, increased cost, and increased the time for the study.

Limitations of the thermoplastic materials were especially exacerbated by the larger socket size used for this study. A reasonable expectation is that smaller shapes would result in stronger sockets since the material would not need to be stretched as much. The correlation between distal socket thickness and strength support this conclusion. However, the fact that the process produces weaker sockets for larger patients is, in itself, a limitation. 
Further, all of these sockets were deemed by their manufacturer to be suitable for delivering to a patient. As such, while these conditions do not apply to all patients, they do affect some patients. Further, the current process of delivering a socket does not appear to consistently account for this effect.

Finally, there were variances in the protocol. Some socket providers did not provide all of the requested sockets. Some provided sockets with additional holes. In these cases, we performed statistical analysis on the effects of these variances and then called them out in this article. In some cases, providers admitted that the socket being delivered was not in some sense "perfect," and in some cases, these providers asked if the provided sockets were "okay." For all these questions, we asked the suppliers to apply the same standard: "Would you deliver this to a patient?”

\section{Assessment of Socket Strength}

\section{Check Sockets}

CSs fabricated by different facilities displayed a significant difference in static force inflection points. Since CSs may or may not be used for dynamic evaluation, not all sockets require a safety level comparable with the passing criterion of ISO 10328 A125 ductile static test force. However, five of the facilities failed, on average, to meet the ISO 10328 at the 5 percent anthropometric level, indicating very low strengths for these sockets. Some CSs were so thin as to be flexible with light finger pressure. With these factors in mind, whether these sockets that fail at below the 5 percent anthropometric criterion and that can be easily deformed with the fingertips can be accurately used to indicate static, let alone dynamic, fit is questionable.

Material analysis indicates that sockets made from PETG produced the highest force inflection points and performed significantly better than sockets made from ThermoLyn rigid. We also found a strong correlation between force inflection values and distal socket thicknesses for PETG. In fact, the sockets constructed from ThermoLyn rigid contained portions that deformed to touch. These areas were approximately $0.4 \mathrm{~mm}$ thick and were located on the distal curvature of the socket above the distal cup region, a common location for buckling and a critical location for prosthetic fit. The ThermoLyn rigid sockets, all constructed using the blister technique, performed least favorably with regards to force inflection points. Orfitrans Stiff was not significantly different from the other materials. Machine-pulled sockets had significantly higher force inflection points than sockets manufactured using other techniques. The facilities that used the machine-pulled fabrication method demonstrated the least amount of variability with an RSD between 3 and 4 percent. Some facilities had sockets that deviated as much as 34 percent in strength. Assuming the correlation between distal thickness and force inflection points, extrapolation indicates that PETG would require a thickness greater than $5.2 \mathrm{~mm}$; Orfitrans Stiff and ThermoLyn rigid, combined for evaluation because of similar material properties [10], would require a thickness greater than $9.8 \mathrm{~mm}$ to satisfy the anthropometric 95 percent ISO 10328 ductile failure mode level for the given socket geometry. The correlation between break energy and distal cup thickness (Figure 8) also indicates that PETG sockets with distal cup thickness greater than $5 \mathrm{~mm}$ produced more favorable outcomes (higher break energy with compression at the distal plane).

The data suggest that material, thickness, and fabrication method were potential contributing factors to the variability between facilities. Within a facility, one potential contributing factor to variability was socket fit. Several CSs (21\%) were considerably undersized compared with the test fixture mold, causing the load to be concentrated higher up on the socket. The load curves for these sockets were slightly altered. The undersized sockets, all constructed from PETG, tended to fail at a faster rate than proper fitting sockets, except for two sockets that were the thickest sockets constructed from PETG.

\section{Copolymer Sockets}

All CPs failed the ISO 10328 A125 static test for ductile materials. In further evaluation of the CP data, all but two facilities had average force inflection points below the anthropometric 5 percent ISO 10328 ductile level. The other two facilities, 02 and 05, had averages below the anthropometric 50 percent ISO 10328 ductile level. The ISO levels may not be a significant concern with CSs if dynamic evaluations are not performed; however, these lower strengths in CPs are a concern because of the common use of copolymer materials for the construction of permanent sockets.

We observed a correlation between average distal thickness and force inflection points for a given fabrication method. According to the trend in Figure 10, sockets fabricated with the drape method appear to be influenced 
more by distal socket thickness than the other fabrication methods. This may be because the additional material left in these sockets to form a seam also forms a thicker section that can act as a load-bearing member in the overall structure. In order to satisfy the anthropometric 95 percent ISO 10328 ductile failure mode criterion, the correlation between distal thickness and force inflection points suggests a copolymer distal (cup) thickness greater than $7.3 \mathrm{~mm}$ would be necessary.

The correlation between break energy and distal cup thickness (Figure 11) suggests that more favorable outcomes (ductile distal compression with high break energy) occurred at distal cup thicknesses greater than $5 \mathrm{~mm}$. Additionally, the correlation between break energy and the ratio of the distal plane thickness to the distal cup thickness (Figure 11) indicates that a ratio of 1.5 appears to be the transition area between compression at the distal plane and compression at the socket's neck curvature. Ratios below 1.5 tend to result in distal plane compression, a more favorable failure location. While this value is likely to depend on the geometry of the specific socket, this further highlights the complexities of the trade-offs that the industry currently faces.

Several CPs (32\%) were smaller than the test fixture mold, resulting in an improper fit. We observed this with sockets from four facilities: two CFAB and two military. Both facilities using the drape fabrication method produced improperly fitting sockets. The improperly fitted CPs did not appear to influence the force inflection points since improperly and properly fitting sockets from the same facility produced comparable results. Distal socket thickness appeared to be a stronger contributor to the force inflection value than sizing.

\section{Definitive Laminated Sockets}

Since DL strengths were not directly correlated with thickness or weight, other factors must contribute to the variability between facilities and within individual facilities. Variation between facilities may be caused by the amount of vacuum pulled during construction, amount of wet-out (saturation of resin into the reinforcement material), type of resin, amount of resin, and type of fiber reinforcement. Resin type, including acrylic, polyester, and modified epoxy, are hard to differentiate in a final product. The reinforcement varies according to carrier (the thickness and amount of threads in each braid). Within a facility, the variation may be caused by the technician and/or the time frame in which the sockets were constructed.
Each technician may use a different lay-up, produce a different amount of wet-out, or use a different amount of resin. Sockets were not necessarily fabricated on the same day by the same technician. The average RSD within a facility was 21 percent.

Two facilities (08 and 09) had DLs that did not fit the testing fixture. Facility 08 produced both undersized and oversized sockets compared with the testing model. Data from this facility indicated that the oversized socket generated lower force compression points than the undersized sockets. Facility 09 had one socket that was undersized.

Previous research suggests that carbon fiber reinforcement material is stronger than fiberglass material [3-4]; however, the combination of reinforcement material and resin produced varying effects. Variation between and within facilities might be caused by different resin, different reinforcement, the level of vacuum during construction, and/or technician technique. Since several facilities did not provide specific fabrication materials and methods information, analysis of these factors was not possible. In a similar study analyzing several laminate reinforcement material and resin combinations, Current et al. indicated that all of the sockets they fabricated using state-of-the-art practices failed the ISO 10328 A100 static test [4]. In contrast, our study contained several sockets that passed the ISO 10328 A125 static test level in a brittle failure mode. Contributing differences included our study's evaluation of larger sockets and the incorporation of a more compliant distal adapter. Both elements reduced the stress concentration at the location of the distal attachment.

\section{Socket Fit Assessment}

An unexpected observation made during this study regarded the percentage of unsuitable sockets we received. Several sockets were not fabricated according to instructions and/or were improperly sized compared with the test fixture mold. This occurred in approximately one quarter of the sockets we analyzed (27 out of 98). In the field, many of these sockets would potentially be classified as unacceptable because of improper socket fit or inadequate fabrication, which would delay delivery of a patient's prosthesis. On the other hand, several patients might have been fitted with the improper sockets, potentially compromising the strength or function of the socket and overall prosthesis. Sanders et al. determined that 7 out of the 10 CFAB facilities they tested produced 
inconsistent transtibial prosthetic sockets when compared with an electronic file [13]. The remaining three CFAB facilities produced consistent sockets; however, one of these facilities produced consistently oversized sockets [13].

We conducted an additional analysis comparing two of the DLs we received; one with acceptable fit and one oversized. We compared these two sockets using digital scanning technology. Because of the extensiveness of the comparison, we conducted this analysis only to quantitatively illustrate the difference in socket fit and not as a complete analysis of all sockets in the study. The analysis was conducted by 3D Engineering Solutions (Cincinnati, Ohio). They scanned the sockets using a Faro Laser Line Probe (FARO Technologies, Inc; Lake Mary, Florida) and compared them with the original CAD/CAM file sent to the facilities. The probe has an accuracy tolerance of $0.080 \mathrm{~mm}$, with a total scanning measurement uncertainty of $0.095 \mathrm{~mm}$. The sockets were sprayed with a light coating of powder to minimize specular reflection, which can cause spurious scan data. Since the sockets contained distal holes and curved trim line edges not present in the original CAD/CAM model, these features were filtered out along with any spurious scan data. This eliminated 2.1 and 4.7 percent of the scan data, respectively. The acceptable socket had a mean point deviation from the CAD/CAM model of $0.23 \pm 0.76 \mathrm{~mm}$. In contrast, the improper socket had a mean point deviation from the CAD/CAM model of $-0.91 \pm 1.47 \mathrm{~mm}$ (negative value indicating oversize). The average deviation of approximately $1 \mathrm{~mm}$ for the oversized socket quantitatively illustrates variability currently experienced with prosthetic sockets and more carefully demonstrated in a previous study [13]. The high variability and broad range of force inflection points suggested a standardized repeatable technique may be warranted to provide people with lower-limb amputation with the best possible prosthetic socket.

\section{Cyclic Loading}

As mentioned earlier, nearly all the CSs we received would have failed the proof test portions of the cyclic loading requirements generally applied to lower-limb prosthetic devices. This supports the logic behind the common practice of reinforcing CSs before dynamic testing.

One CP actually passed the cyclic loading criteria for ISO 10328 at A125 levels. Also, most patients would have smaller limb dimensions than those in the test shape for this study, thus resulting in thicker material on the dis- tal end. However, this one socket was made from a bell on a socket machine, while most of the other CPs we received would have failed under both static and cyclic loading. This dichotomy of low static strength combined with the ability of some of these sockets to pass cyclic testing, seems at odds and calls into question the common acceptance of copolymer as a definitive socket material. However, that the CPs tended to fail in a ductile manner may indicate why they continue to be trusted by many practitioners for some of their patients. If they do fail, they generally seem to fail in a soft and gradual manner that is less likely to cause harm to a patient than some other failure options. These observations indicate a potential necessity to carefully consider the needs of a given patient and the fabrication techniques available before delivering a CP to a patient for use as a long-term definitive socket.

The static performance of the laminated sockets as a class, and the performance of the single sample tested cyclically, indicates that most carbon laminated sockets would probably survive the cyclic loading requirements of ISO 10328 at the A125 level. This is encouraging in light of their prevalent use in practice and the current lack of an alternative.

\section{Socket Variability}

In short, the strength and fit of prosthetic sockets currently delivered to lower-limb prosthetic patients today largely varies. There appear to be three primary contributors to this variability: the range of materials used to fabricate these sockets, the range of techniques used to fabricate these sockets, and the variability of these techniques. These results suggest at least three possible routes for improving the product delivered to a patient. These suggestions follow from the goals of improving normative performance and then reducing the variability of the performance.

The first step could be an industry-wide evaluation of the efficacy of various methods and materials. This information could then be used to suggest industry-wide best practices. The fact that some providers can create sockets with significantly higher strengths than others indicates that some practices are simply more effective in making stronger and more accurate prosthetic sockets. Industry-wide evaluation of best practices could greatly improve the average quality of sockets delivered to patients. While this article does identify some possible improvements, the focus is on the overall trends and not designed to look at 
specific practices inside of a given provider. Further study of the specific practices used to manufacture sockets may be warranted. This avenue to improvement may be hampered by the fact that a majority of the best performers were CFAB facilities, whose practices may be considered trade secrets. However, an evaluation of a larger set of other socket providers should identify these same practices and would lead to a significant improvement in socket strength. Unfortunately, while this could greatly improve the quality of the average socket, the data indicate that even the best performers in the field do not appear to consistently provide sockets that can be counted on to withstand the loads that other prosthetic components are required to withstand.

Second, the fact that the RSD in socket strength for CPs from individual providers was as high as 70 percent indicates that there is room for improvement in the way that individual practices are applied. Once specific best practices are identified, optimizing these practices may reduce the variability of the resulting sockets. While a statistical analysis indicated that most of the providers did not reliably produce laminated sockets that meet the ISO 10328 A125 loading criteria, a number of facilities produced sockets with average strengths well above this threshold. Reducing variability in the process could result in a process that consistently meets the criteria that the rest of the prosthetic limb is required to meet.

The third step is to look for new materials and practices with higher strengths or tighter process controls. In the case of composite laminated sockets, the data indicated that thickness of the socket had little bearing on the strength of the final product. This may indicate that a typical socket has more resin than necessary. Such a conclusion would indicate that an additional layer of carbon could significantly increase the strength of the socket, without increasing the overall weight or dimensions of the final socket. This said, the factors that affect the strength and fit of a given socket are numerous and, at times, contradictory. Real world business concerns also interfere. The three following examples drawn from this study are exemplary.

First, increasing material thickness in the distal portions of thermoformable sockets can go a long way toward increasing the strength of these sockets. Unfortunately, increasing the thickness of a socket in the wrong portion of the distal socket tends to result in failure modes that may expose the patient to harm in the event of an extreme occurrence such as a fall. Further, anecdotal evidence currently seems to indicate that thicker sections of some of the thermoformable materials are more susceptible to brittle failures and the resulting sharp features caused by such failures (Figures 8 and 11).

Second, thermoformed sockets manufactured by draping were generally stronger than those manufactured by blister techniques. However, sockets made by draping were also generally judged to be poor fits to the standardized test residual limb. The type of balancing act indicated by these examples may be more than a technician can be reasonably expected to control while he holds a piece of molten plastic in his hands and tries to form it in the 5 to $10 \mathrm{~s}$ that he has to vacuum form the socket. For this reason, studies of newer production materials and techniques are probably warranted.

Third, using a socket manufacturing unit (SMU) to manufacture sockets often increased socket strength and reduced variability. This would seem to be a very favorable outcome. However, SMUs are generally slow and expensive. As a result, they tend to be too expensive for a PP facility that could afford to wait for slower build times and too slow for a CFAB facility that could afford the additional overhead.

In all, the impressive blend of art and technology currently applied to the design of each socket has converged on multiple techniques that can usually produce a socket that typically performs satisfactorily. That such a complicated blend of materials science, mechanical design, biomechanics, and art has been accomplished largely by numerous ad hoc experiences and word of mouth is a testament to the care and the personal stake that individual technicians and practitioners place in each socket that they deliver to their patients. However, this article shows that not all of these solutions are equal. Further, while much improvement can be made in the field as a whole with some simple material and process choices, the data further indicate that even the best performers using the current state-of-the-art do not consistently produce lowerlimb prosthetic sockets that can reliably support the loads required for the components that are mounted to them. Future work on materials, process optimization, and research into new processes for manufacturing sockets will likely be necessary before a prosthetic socket can be expected to pass the mechanical testing that the other components in a lower-limb prosthetic are already required to survive. 


\section{Summary}

The results from the socket static testing demonstrate that the strength of sockets delivered to lower-limb prosthetic patients varies considerably. The RSD for average strengths delivered from different facilities was 49 percent for CSs, 61 percent for CPs, and 25 percent for DLs. These values represent the amount of variability in socket strength across the prosthetic field as a result of differing methods, materials, process variability, and skill. Further, the SD within many individual facilities was high regardless of socket type, fabrication method, or material. Within facilities the average RSD was 15 percent for CSs, 42 percent for CPs, and 21 percent for DLs. These values represent the amount of variability in socket strength as a result of process and material variability.

Distal socket thickness, material, and fabrication methods influenced CS strengths. PETG produced significantly stronger sockets than ThermoLyn rigid. Sockets made from ThermoLyn rigid or Orfitrans Stiff require greater thicknesses to create sockets with comparable strength to a similar PETG socket. The machine-pulled fabrication method produced stronger sockets than those made by blister fabrication methods. This is likely a result of better control over material thickness, deformations, and strains, which in turn resulted in more consistent and thicker sockets.

Fabrication method and distal socket thickness affected CP strengths. Machine-pulled and drape-fabricated sockets were significantly stronger than blister fabricated sockets. In general, drape and machine-pulled sockets had thicker distal socket thicknesses. Draped sockets also appeared to be influenced more by distal thickness than other fabrication methods. Unfortunately, this additional strength appeared to come at the cost of reduced dimensional accuracy.

DL strengths were not influenced by thickness, implying that heavier, thicker sockets are not necessarily the strongest for this class of socket. The strength of these sockets can be attributed to many factors including, but not limited to, the type and amount of reinforcement material, type of resin used, matrix bonding, fiber orientation, lay-up, and degree of wet-out. Many of these are difficult to control and could lead to the observed variability. Only half of the DLs passed the ISO 10328 A125 loading criteria for brittle failure modes. Extensive analysis of reinforcement material and resin combination was beyond the scope of this study.
One observation we made was that currently, no widely used process in the field consistently produces a socket that would pass the requirements of ISO 10328. In fact, a vast majority of sockets received for this study fell far short of meeting this standard. A worthy debate is whether or not this high level of performance is needed in a lower-limb prosthetic socket. However, careful evaluations by standards groups have decided that all other components in a patient's prosthesis must do so.

The goal of this article was not to evaluate the individual combinations of materials and methods but to evaluate the variability in socket performance within the prosthetic field and to identify possible routes to improved patient care. Several authors have explored alternative fabrication configurations of laminated sockets and the effects on strength [3-4,14-16]. This article evaluates the state-of-the-art regarding prosthetic sockets by collecting samples from across the field. We determined that prosthetic socket construction and performance is not consistent across the field and can vary considerably between and within facilities. Also, the article provides insight into the static failure loads of prosthetic sockets produced by widely accepted fabrication methods and materials. Further investigation is required to isolate and completely evaluate specific combinations of methods and materials, especially for DLs. However, when looking across the industry, the choice between nyglass and carbon reinforcement, materials with significantly different strengths [4], did not result in sockets with statistically different strengths. This indicates that the current practices used by many socket manufacturers do not capture the potential of the materials that they are using, in some cases by a wide margin.

\section{CONCLUSIONS}

This article examines the quality of the sockets for lower-limb prostheses. We analyzed the static strength of CSs, CPs, and DLs produced in different facilities using current state-of-the-art fabrication methods. The statistically analyzed results demonstrated high variability and, in many cases, inadequate strength according to ISO 10328 loading criteria. This information provides a helpful foundation for the industry in its attempts for improvements. Possible routes for improvement include industry-wide evaluation of the efficacy of various methods and materials, used to suggest industry-wide best 
practices; optimization of practices to reduce variability; and exploration of new material and practices with higher strengths or tighter process controls.

\section{ACKNOWLEDGMENTS}

\section{Author Contributions:}

Study concept and design: M. L. Haynes, M. J. Gerschutz, D. Nixon, J. M. Colvin.

Acquisition of data: D. Nixon.

Analysis and interpretation of data: M. J. Gerschutz, M. L. Haynes.

Drafting of manuscript: M. J. Gerschutz, M. L. Haynes.

Critical revision of manuscript for important intellectual content:

M. J. Gerschutz, M. L. Haynes, J. M. Colvin.

Statistical analysis: M. J. Gerschutz.

Financial Contributions: All authors are employed by The Ohio Willow Wood Company, which has an internal CFAB facility. Even though none of the authors work in the CFAB facility and the CFAB facility's sockets were not evaluated in the submitted article, knowledge gained from the submitted article will assist in improving the product quality of the CFAB facility and potentially other CFAB facilities. The study sponsor had no involvement in the study design, the data collection and analysis, interpretation of data, the writing of the report, or the decision to submit the report for publication.

Funding/Support: This material was based on work conducted by The Ohio Willow Wood Company and made possible by a contract grant awarded and administered by the U.S. Army Medical Research and Materiel Command and the Telemedicine and Advanced Technology Research Center (grant W81XWH-08-10700).

Additional Contributions: The authors wish to acknowledge Dave Holloway for his assistance in the acquisition of data.

\section{REFERENCES}

1. Mak AF, Zhang M, Boone DA. State-of-the-art research in lower-limb prosthetic biomechanics-socket interface: A review. J Rehabil Res Dev. 2001;38(2):161-74. [PMID:11392649]

2. Sanders JE, Greve JM, Mitchell SB, Zachariah SG. Material properties of commonly-used interface materials and their static coefficients of friction with skin and socks. J Rehabil Res Dev. 1998;35(2):161-76. [PMID:9651888]

3. Phillips SL, Craelius W. Material properties of selected prosthetic laminates. J Prosthet Orthot. 2005;17(1):27-32. http://dx.doi.org/10.1097/00008526-200501000-00007

4. Current TA, Kogler GF, Barth DG. Static structural testing of trans-tibial composite sockets. Prosthet Orthot Int. 1999;23(2):113-22. [PMID:10493138]

5. ISO 10328:2006. Prosthetics-Structural testing of lowerlimb prostheses-Requirements and test methods [Internet]. Geneva (Switzerland): International Organization for Standardization; 2006 [updated 2011 Aug 10]. Available from: http://www.iso.org/iso/iso catalogue/catalogue tc/ catalogue detail.htm?csnumber $=38708$

6. Graebner RH, Current TA. Relative strength of pylon-tosocket attachment systems used in transtibial composite sockets. J Prosthet Orthot. 2007;19(3):67-74. http://dx.doi.org/10.1097/JPO.0b013e3180cfe8da

7. Coombes AG, MacCoughlan J. Development and testing of thermoplastic structural components for modular prostheses. Prosthet Orthot Int. 1988;12(1):19-40.

[PMID:3399367]

8. Pritham CH. Thermoplastics in lower extremity prosthetics: Equipment, components, and techniques. J Prosthet Orthot. 1990;3(1):14-21. http://dx.doi.org/10.1097/00008526-199000310-00006

9. Coombes AG, Greenwood CD, Shorter JJ. Plastic materials for external prostheses and orthoses. In: Wise DL, Trantolo DJ, Altobelli DE, Yaszemski MJ, Gresser JD, editors. Human biomaterials applications. 1st ed. Totawa (NJ): Humana Press; 1996. p. 215-46.

10. Gerschutz MJ, Haynes ML, Nixon DM, Colvin JM. Tensile strength and impact resistance properties of materials used in prosthetic check sockets, copolymer sockets, and definitive laminated sockets. J Rehabil Res Dev. 2011;48(8): 987-1004. [PMID:22068374] http://dx.doi.org/10.1682/JRRD.2010.10.0204

11. Goh JC, Lee PV, Ng P. Structural integrity of polypropylene prosthetic sockets manufactured using the polymer deposition technique. Proc Inst Mech Eng H. 2002;216(6): 359-68. [PMID:12502000] http://dx.doi.org/10.1243/095441102321032157

12. Neo LD, Lee PV, Goh JC. Principal structural testing of trans-tibial prosthetic assemblies: Specimen preparation. Prosthet Orthot Int. 2000;24(3):241-45. [PMID:11195360] http://dx.doi.org/10.1080/03093640008726554

13. Sanders JE, Rogers EL, Sorenson EA, Lee GS, Abrahamson DC. CAD/CAM transtibial prosthetic sockets from central fabrication facilities: How accurate are they? J Rehabil Res Dev. 2007;44(3):395-405. [PMID:18247236] http://dx.doi.org/10.1682/JRRD.2006.06.0069

14. Berry DA. Composite materials for orthotics and prosthetics. Orthot Prosthet. 1987;40(4):35-43.

15. Taylor D. Lower-limb prosthetics-Mechanical testing prosthetic sockets. 2005 Journal of Proceedings; 2005 Mar 16-19; Orlando, FL. Washington (DC): American Academy of Orthotists and Prosthetists; 2005. p. 34-37.

16. Faulkner VW, Field M, Egan JW, Gall NG. Evaluation of high strength materials for prostheses. Orthot Prosthet. 1986;40(4):44-58.

Submitted for publication May 16, 2012. Accepted in revised form September 1, 2011. 
JRRD, Volume 49, Number 3, 2012

This article and any supplementary material should be cited as follows:

Gerschutz MJ, Haynes ML, Nixon D, Colvin JM. Strength evaluation of prosthetic check sockets, copolymer sockets, and definitive laminated sockets. J Rehabil
Res Dev. 2012;49(3):405-26.

http://dx.doi.org/10.1682/JRRD.2011.05.0091

\begin{tabular}{|c|c|}
\hline $\begin{array}{l}\text { Au surassions screened Br. } \\
\text { iThenticate }\end{array}$ & ef НЕмвЕ \\
\hline 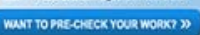 & $\begin{array}{l}\text { CROSSSREF.ORG } \\
\text { THE CITATION LIIKING BACKEOME }\end{array}$ \\
\hline
\end{tabular}

